Article

\title{
Power Sensitivity Analysis of Multi-Frequency, Multi-Polarized, Multi-Temporal SAR Data for Soil-Vegetation System Variables Characterization
}

\author{
Fulvio Capodici ${ }^{1, *}(\mathbb{D})$, Antonino Maltese ${ }^{1}(\mathbb{D})$, Giuseppe Ciraolo ${ }^{1}\left(\mathbb{D}\right.$, Guido $^{\prime}$ Urso $^{2}$ and \\ Goffredo La Loggia ${ }^{1}$ \\ 1 Dipartimento di Ingegneria Civile, Ambientale, Aerospaziale, dei Materiali (DICAM), Università degli Studi \\ di Palermo, Viale delle Scienze bld, 8-90128 Palermo (PA), Italy; antonino.maltese@unipa.it (A.M.); \\ giuseppe.ciraolo@unipa.it (G.C.); goffredo.laloggia@unipa.it (G.L.L.) \\ 2 Dipartimento di Agraria, Università di Napoli "Federico II", Via Università, 100 I-80055 Portici (NA), Italy; \\ durso@unina.it \\ * Correspondence: fulvio.capodici@unipa.it; Tel.: +39-091-2389-6547
}

Received: 10 April 2017; Accepted: 28 June 2017; Published: 4 July 2017

\begin{abstract}
The knowledge of spatial and temporal variability of soil water content and others soil-vegetation variables (leaf area index, fractional cover) assumes high importance in crop management. Where and when the cloudiness limits the use of optical and thermal remote sensing techniques, synthetic aperture radar (SAR) imagery has proven to have several advantages (cloud penetration, day/night acquisitions and high spatial resolution). However, measured backscattering is controlled by several factors including SAR configuration (acquisition geometry, frequency and polarization), and target dielectric and geometric properties. Thus, uncertainties arise about the more suitable configuration to be used. With the launch of the ALOS Palsar, Cosmo-Skymed and Sentinel 1 sensors, a dataset of multi-frequency ( $\mathrm{X}, \mathrm{C}, \mathrm{L}$ ) and multi-polarization (co- and cross-polarizations) images are now available from a virtual constellation; thus, significant issues concerning the retrieval of soil-vegetation variables using SAR are: (i) identifying the more suitable SAR configuration; (ii) understanding the affordability of a multi-frequency approach. In 2006, a vast dataset of both remotely sensed images (SAR and optical/thermal) and in situ data was collected in the framework of the AgriSAR 2006 project funded by ESA and DLR. Flights and sampling have taken place weekly from April to August. In situ data included soil water content, soil roughness, fractional coverage and Leaf Area Index (LAI). SAR airborne data consisted of multi-frequency and multi-polarized SAR images ( $\mathrm{X}, \mathrm{C}$ and $\mathrm{L}$ frequencies and $\mathrm{HH}, \mathrm{HV}, \mathrm{VH}$ and $\mathrm{VV}$ polarizations). By exploiting this very wide dataset, this paper, explores the capabilities of SAR in describing four of the main soil-vegetation variables (SVV). As a first attempt, backscattering and SVV temporal behaviors are compared (dynamic analysis) and single-channel regressions between backscattering and SVV are analyzed. Remarkably, no significant correlations were found between backscattering and soil roughness (over both bare and vegetated plots), whereas it has been noticed that the contributions of water content of soil underlying the vegetation often did not influence the backscattering (depending on canopy structure and SAR configuration). Most significant regressions were found between backscattering and SVV characterizing the vegetation biomass (fractional cover and LAI). Secondly, the effect of SVV changes on the spatial correlation among SAR channels (accounting for different polarization and/or frequencies) was explored. An inter-channel spatial/temporal correlation analysis is proposed by temporally correlating two-channel spatial correlation and SVV. This novel approach allowed a widening in the number of significant correlations and their strengths by also encompassing the use of SAR data acquired at two different frequencies.
\end{abstract}

Keywords: backscattering; soil water content; surface roughness; leaf area index; sensitivity analysis 


\section{Introduction}

A positive impact on hydrology as well as on modern agricultural practices can be achieved by monitoring spatial and temporal dynamics of some land surface variables such as soil water content, $m_{\mathrm{v}}$, and vegetation. Despite the fact that synthetic aperture radar (SAR) allows acquiring in all weather conditions, unassessed strengthenings of the relations among backscattering, $\sigma^{\circ}$, at different frequencies and polarizations and soil-vegetation variables (SVV) are limiting the operational application of SAR. Indeed, SAR configuration controls the wave-target interactions [1,2] and, thus, affects models' assessments depending on its frequency, polarization and acquisition geometry.

The dependence of bare soils $\sigma^{\circ}, \sigma^{\circ}$, on both water content and surface roughness was modeled by several authors [1-5]. However, the need of a prior knowledge of the soil surface roughness could reduce the feasibility of SAR techniques [4,6-8]. Indeed, reliable roughness measures are hardly achievable: (i) in situ measurements with contact methods (e.g., grid board [9]) are point based and usually not representative at plot scale; (ii) innovative methodologies (e.g., non-contact ultrasonic profiling) are capable of describing wide areas but still economically expensive (i.e., requiring airborne acquisitions).

Over vegetated areas an additional $\sigma^{\circ}$ contribution, $\sigma^{\circ} \mathrm{V}$, needs to be taken into account. Several authors, investigated $\sigma^{\circ} \mathrm{V}$ by setting up theoretical models [10-12] schematizing the vegetation as simple targets of known geometry (such as plates and cylinders). Simple empirical models, avoiding a rigorous mathematical and geometrical simulation of the canopy, are often based on ratios of bands acquired at different polarizations [13-16]. The need of a priori characterization of vegetation structure (hardly achievable through in situ campaigns) reduces the operational use of SAR in agriculture.

In recent years, several researches focused on $m_{\mathrm{V}}$ quantification (over both bare, B, and vegetated, $\mathrm{V}$, soils) explored different SAR configurations and approaches by testing (Table 1): (i) the use of temporal indices; (ii) the integration of passive microwaves and in situ data; (iii) different $\sigma^{\circ}$ models; (iv) the conjunct use of complex statistical models (such as Bayesian approach); (v) empirical fitting and ratio methods (refer to the Appendix A for symbols and acronyms). There were several approaches: empirical, EA; semi-empirical, SEA; theoretical, TA; polarimetric, PA; statistical SA, these latter employing Neural Networks, polarimetric indices or, channels ratio. Some authors calibrated $\sigma^{\circ}$ models such as: IEM (Integral Equation Model [4]), WC (Water-Cloud model [17]); GO (Geometrical Optics [4]); Dubois [1]; Oh [2,3]; RTM (Radiative Transfer Model); MIMICS (Michigan Microwave Canopy Scattering model [18]). Several authors separated soil and vegetation contributions by exploiting more than two polarizations (single frequency), by parameterizing the WC through in situ data.

All these approaches are usually based on regression analyses among $\sigma^{\circ}$ and SVV (i.e., soil roughness, water content, fractional cover and leaf area index). It is well known that SAR configuration (acquisition geometry, frequency and polarization) plays a fundamental role in the $\sigma^{\circ} \mathrm{vs}$. SVV relationship; thus it is expected that modifications of some SVV change also the spatial correlation between data acquired with different configurations.

Based on this evidence, this paper firstly aims to quantify the strength of the relation among $\sigma^{\circ}$ and four SVV (dynamic and single regression analyses) over bare and vegetated soils, over a wide range of cultivars and for different SAR configurations. These first sections are tailored to address: (i) frequencies and polarizations showing the highest sensitivities of $\sigma^{\circ}$ to the dynamic of the selected SVV; (ii) SAR configurations suitable to estimate SVV changes; (iii) frequencies and polarizations carrying redundant information.

Afterwards, the paper shows the effect of SVV changes on the spatial correlation among SAR channels and proposes, as novel approach, the use of temporal regressions of two-channel spatial correlations vs. SVV to explore any improvement achievable compared to the single-channel regression approach. 
Table 1. $m_{\mathrm{v}}$ retrieval using SAR: overview table on previous studies. Accuracy is reported in terms of: determination coefficient, $r^{2}$; correlation, $r$; root mean square error, rmse; average absolute deviation, aad; and mean square error, mse. For detailed notes please refer to Appendix A.

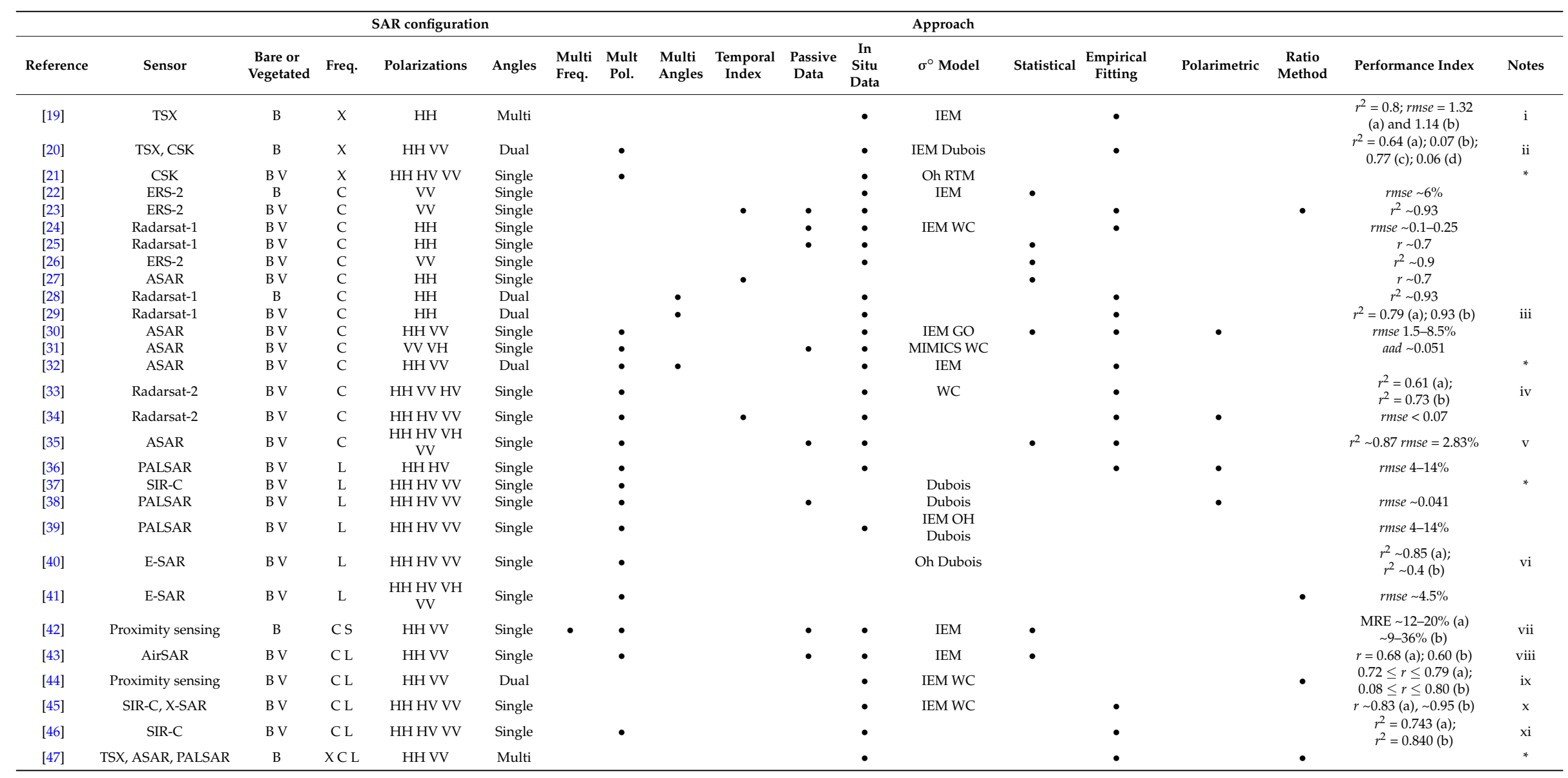




\section{Study Area}

In situ and SAR data have been collected on the $24 \mathrm{~km}^{2}$ DEMMIN (Durable Environmental Multidisciplinary Monitoring Information Network) test site (Figure 1). The site is hosted by a farm located in Mecklenburg-Western Pomerania in North-Eastern Germany (Görmin farm, $53^{\circ} 59^{\prime} 33^{\prime \prime} \mathrm{N}-13^{\circ} 16^{\prime} 40^{\prime \prime} \mathrm{E}$, EPSG 4326).

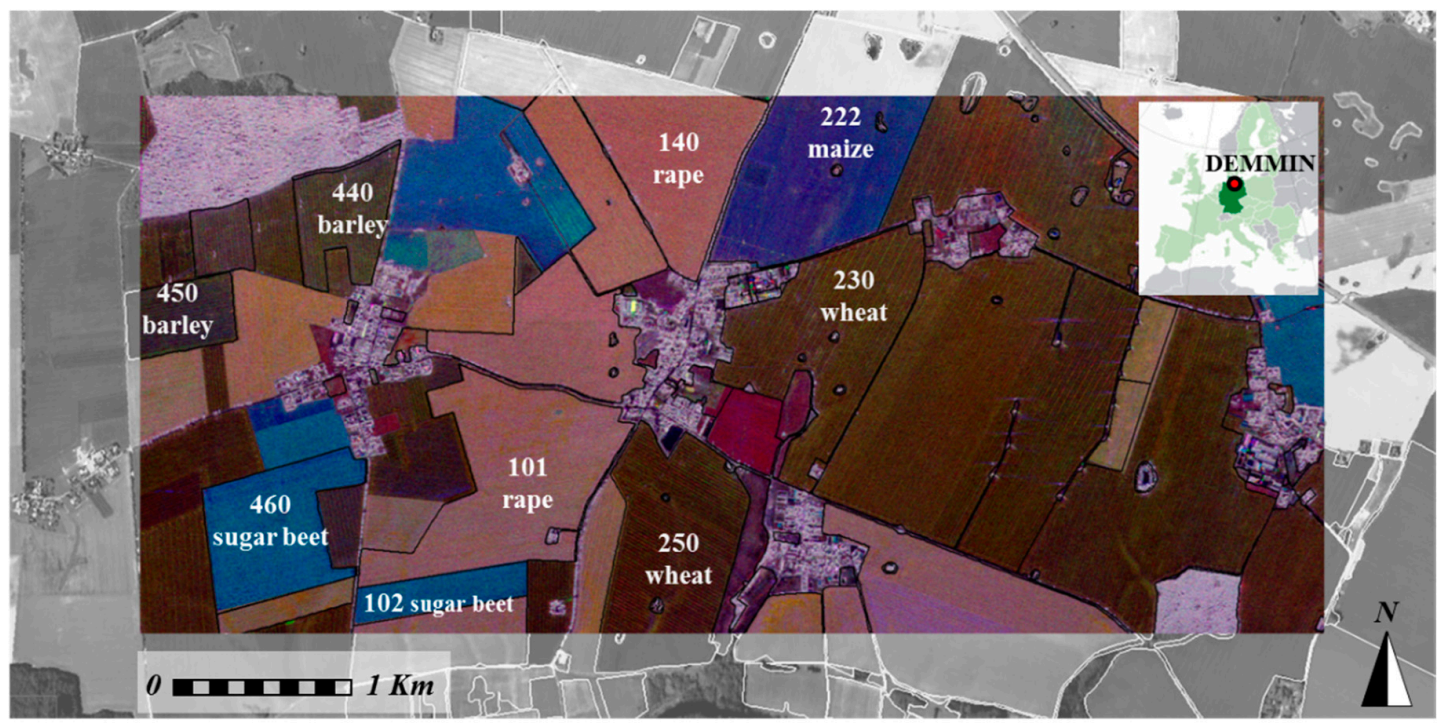

Figure 1. $\mathrm{L}_{\mathrm{HV}}$ diachronic composition of the DEMMIN test-area (R: 24 May; G: 21 June; B: 26 July). Labels indicating crop IDs and cultivars are over-imposed.

Nine crops were monitored over one or more plots (the plot identifier is reported between brackets): wheat (IDs 230 and 250), rape (IDs 101 and 140), barley (IDs 440 and 450), maize (ID 222) and sugar beet (IDs 102, 460). Sowing and harvesting dates are reported in Table 2. Noticeable, these cultivars are characterized by different vegetation architecture. Main soil textures in the Görrmin area were loamy sand and sandy loam. Within this area, the 9 monitored plots are characterized by loamy sand texture. In particular, the soil texture of plots 222, 450 and 140 is predominantly loamy sand; plot 460 is characterized by loamy sand and slightly loamy sand soil; whereas the other plots are characterized by both loamy sand and strong loamy sand soils.

Table 2. Sowing and harvesting dates for main crops during the investigation period; plots IDs are reported within brackets.

\begin{tabular}{ccc}
\hline Crop (ID) & Sowing Dates & Harvest Dates \\
\hline Wheat $(230,250)$ & 5 September-31 October & 15-31 August \\
Barley $(440,450)$ & 12-25 September & 15-25 July \\
Rape $(101,140)$ & 8 August-5 September & 28 July-10 August \\
Maize $(222)$ & 20 April-5 May & 25 September-10 October \\
Sugar beet $(102,460)$ & 25 March-20 April & 25 September-31 October \\
\hline
\end{tabular}

\section{Materials}

Data have been collected between April and August 2006 in the framework of the AgriSAR 2006 project (funded by the European Space Agency, ESA) primarily planned to address programmatic needs of Sentinel-1 two-satellite constellation. AgriSAR 2006 campaign was specifically tailored to investigate $\sigma^{\circ}$ dynamic throughout the crop-growing season. The dataset includes weekly in situ measures and airborne SAR and optical images. 
In particular, in situ data have been collected by the Leibnitz-Zentrum für Agrarlandschaftsforschung (ZALF) and the University of Kiel (Christian-Albrechts-Universität, Department of Geography) almost simultaneously to SAR and optical flights. Measurements of $m_{\mathrm{v}}$ (at 0-5 and 5-10 cm below ground level, b.g.1.), soil surface roughness, fractional cover, $F_{\mathrm{V}}$, and $L A I$ were acquired by the research teams along 16 campaigns. In situ $L A I$ and $m_{\mathrm{v}}$ were measured using a LICOR-2000 and a portable IMKO TRIME-FM TDR respectively, root mean square of roughness height, $h^{\prime}$, was characterized with a laser profiler and a Rollei d7 metric digital stereoscopic system [48]. A TDR probe (IMKO TRIME-ES, theoretical accuracy of $\pm 0.01- \pm 0.03 \mathrm{~m}^{3} \mathrm{~m}^{-3}$ ) was installed from the Ludwig-Maximilians Universitat München (LMU) and the University of Kiel on fields 102 (sugar beet) and 250 (wheat) providing measures of $m_{\mathrm{v}}$ at 5 depths $(5,9,15,25$ and $47 \mathrm{~cm}$ b.g.l.) with a temporal resolution of half an hour. Approximately 1150 measurements were executed, equally spread among plots and acquisition times. In particular, 24 measurements were carried out for each in situ campaign; for each plot, always the same locations were taken into account; 36 measurements per plot was carried out during the whole in situ campaign for each SVV. The sugar beet field was completely bare from the first campaign in 19 April until 11 May ( $F_{\mathrm{V}}$ reached 10\% in 7 June); maize field was completely bare until the end of May. Other fields were vegetated until July; rape and barley were harvested during the airborne SAR campaign (Figure 2).

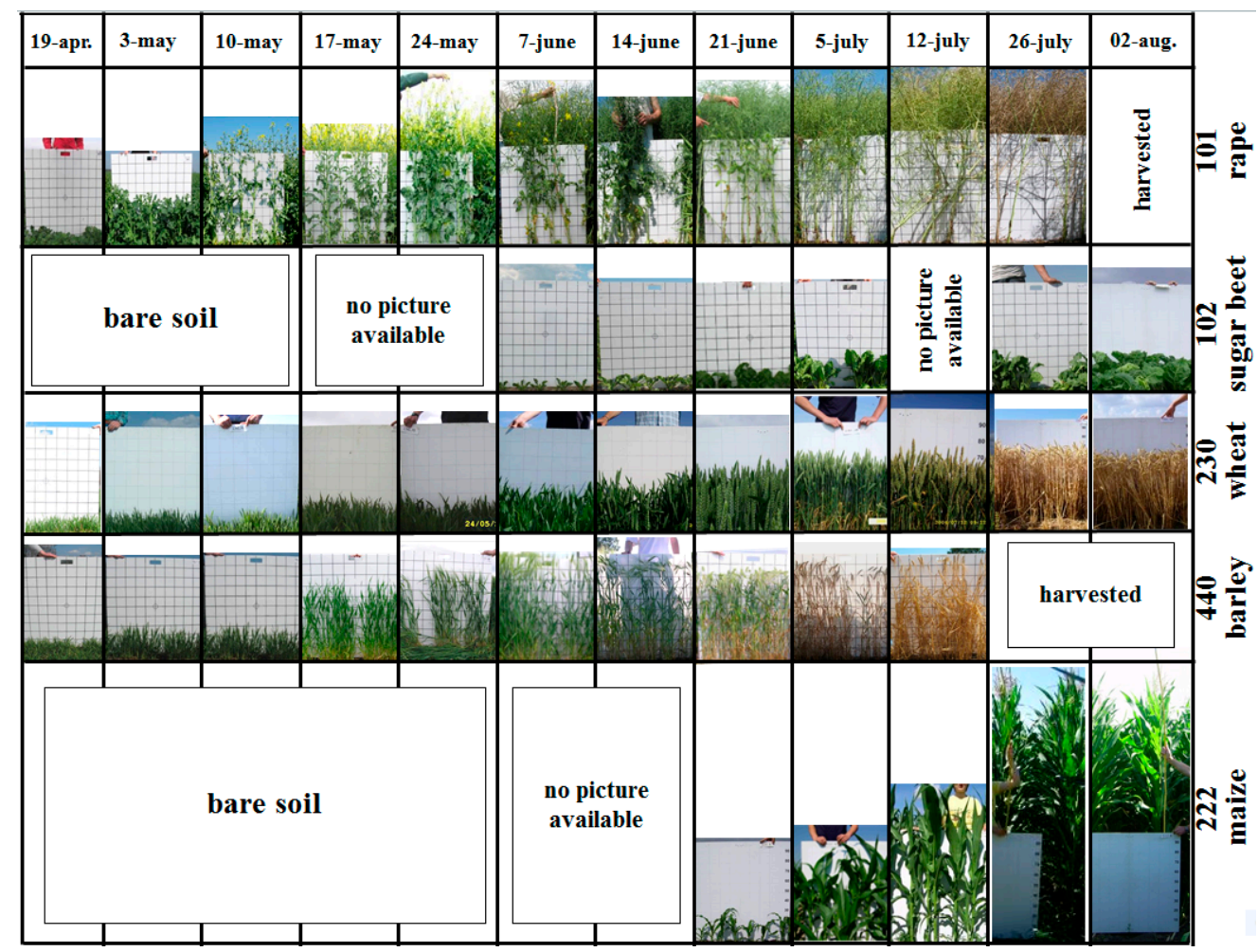

Figure 2. Temporal photo sequence of some Görmin's fields. Pictures were collected during the investigation periods by ZALF and LMU institutes; the white gridded panel $(1 \mathrm{~m} \times 1 \mathrm{~m}$ size, $10 \mathrm{~cm} \times 10 \mathrm{~cm}$ grid resolution) allows estimating the vegetation height evolution.

During the investigation three drying periods occurred; $m_{\mathrm{v}}$ varies in the range [0.34-0.06 $\mathrm{m}^{3} \mathrm{~m}^{-3}$ ] with some differences among fields. In maize crop, $m_{\mathrm{v}}$ was higher than in other fields, probably only due to the root-zone water dynamics of this cultivar (the soil texture was similar to the other monitored plots); $m_{\mathrm{v}}$ in barley, wheat, sugar beet and rape fields behaves similarly during the whole period. Finally, temporal trends of $h^{\prime}$ over barley, rape and wheat fields are quite similar; whereas $h^{\prime}$ exhibits higher values and different temporal behavior over maize and sugar beet (Figure 3). 
The SAR dataset includes 120 images acquired in X, C and L bands (central wavelengths: 2, 5 , and $21 \mathrm{~cm}$ respectively) in dual polarization ( $\mathrm{HH}$ and $\mathrm{VV}$ for $\mathrm{X}$ band) and in quad-polarization ( $\mathrm{HH}, \mathrm{VV}, \mathrm{VH}$ and $\mathrm{HV}$ for $\mathrm{C}$ and $\mathrm{L}$ bands). Flights were weekly carried out from the 9th of April to the 2nd of August by an airborne E-SAR (Experimental SAR), operated by the German Aerospace Center (Deutsches Zentrum für Luft- und Raumfahrt-DLR). The E-SAR sensor was on board a Do228 aircraft; although a total of 16 radar flights were executed during the AgriSAR 2006 campaign, the 12 performed in the E-W direction were considered in this research. The deployment of corner reflectors of $20 \mathrm{~cm} \times 20 \mathrm{~cm}$ during one of the in situ campaigns allowed obtaining multi-look, geo-coded and calibrated $\sigma^{\circ}$ products at a raw spatial resolution, $R_{\mathrm{S}}$, of $2 \mathrm{~m}$.
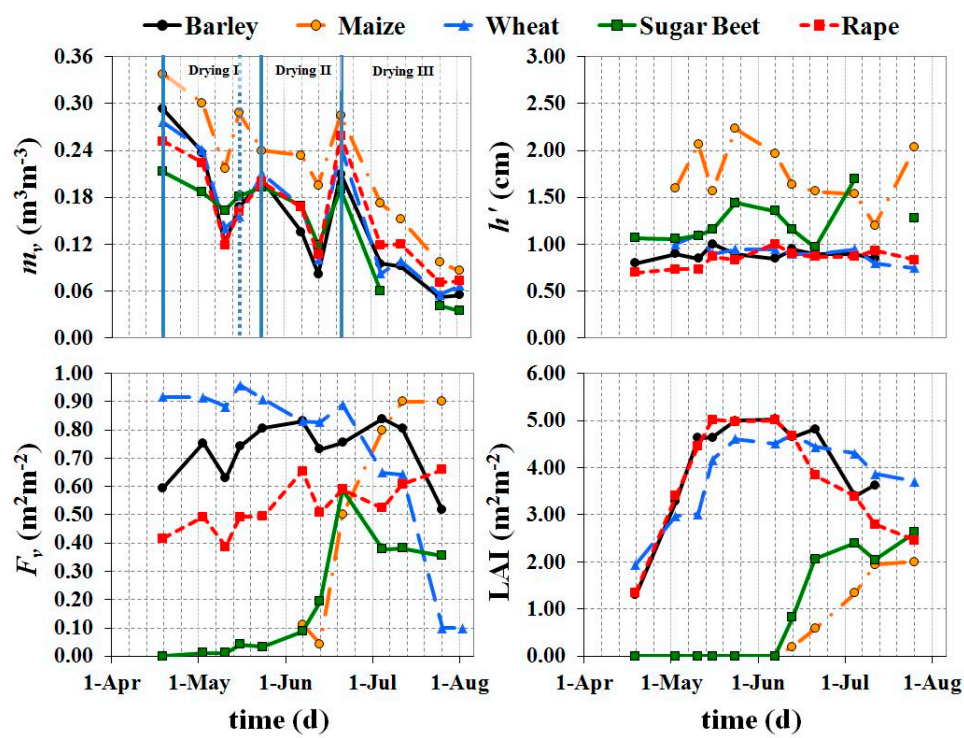

Figure 3. Temporal dynamic of spatially averaged $m_{\mathrm{v}}, h^{\prime}, F_{\mathrm{v}}$ and $L A I$. Blue bars mark $m_{\mathrm{v}}$ peaks separating consecutive drying periods occurred at all crops except for maize in which the second drying period was shorter (see the dashed bar).

During the airborne SAR acquisitions, high variability of $m_{\mathrm{V}}, F_{\mathrm{V}}$ and $L A I$ occurred over both bare and vegetated soils, including different cultivars. Thus, AgriSAR 2006 dataset allows investigating (i) how $\sigma^{\circ}$ is controlled by changes of SVV and, (ii) how SAR configuration (acquisition geometry, frequency and polarization) rules the relationships between $\sigma^{\circ}$ and SVV.

\section{Methods}

For bare soils, $h^{\prime}$ and $m_{\mathrm{v}}$ were included in the analysis; whereas, over vegetation the behavior of $\sigma^{\circ}$ was assessed under a wide range of $m_{\mathrm{v}}$ for different cultivars with varying $h^{\prime}, L A I$, and $F_{\mathrm{v}}$.

Different data analyses were carried out: (i) dynamic analysis of both $\sigma^{\circ}$ and SVV over all fields and over a selected plot; (ii) single regressions between $\sigma^{\circ}$ and SVV; (iii) single regression analysis between inter-channel spatial correlation and SVV at plot scale.

\subsection{Data Aggregation}

As a preliminary step, images were spatially averaged to reduce the speckle. Although several filters have been proposed to this aim [49-53] a simple spatial averaging technique was preferred. Indeed, the spatial aggregation limits inaccuracies in the comparison between $\sigma^{\circ}$ and in situ data due to georeferencing errors and GPS positioning uncertainties, respectively. The more appropriated $R_{\mathrm{S}}$ was selected based on the values assumed by the Moran index $I_{M}$ [54] and the speckle index, $I_{S}$ [55]. 


\subsection{Dynamic Analyses}

This section is focused on the investigation of $\sigma^{\circ}$ temporal behavior. In the first subsection, $\sigma^{\circ}$ dynamic was evaluated at different frequencies and polarizations during the whole period for varying SVV. Subsequently, the $\sigma^{\circ}$ temporal dynamic is qualitatively compared to SVV changes for two selected plots.

\subsubsection{Dynamic Analysis: All Plots}

Firstly, it was analyzed the $\sigma^{\circ}$ dynamic at different frequencies and polarizations (hereinafter referred to as channel) during the whole period, in which variations of $m_{\mathrm{v}}, h^{\prime}, L A I$ and $F_{\mathrm{v}}$ occurred.

For each plot the $\sigma^{\circ}$ range of variability, $\Delta \sigma^{\circ}$ plot, was evaluated. Then, for each channel, metrics such us the average of $\Delta \sigma^{\circ}$ plot,$\Delta \sigma^{\circ}$ avg, and standard deviation of $\Delta \sigma_{\text {plot }}^{\circ} \Delta \sigma^{\circ}$ stdev, were quantified. The higher $\Delta \sigma^{\circ}$ avg the more the channel sensitivity to SVV changes, the higher $\Delta \sigma^{\circ}$ stdev the more heterogeneity among plots. The corresponding metrics computed on $\Delta h^{\prime}, \Delta m_{\mathrm{v}}, \Delta F_{\mathrm{v}}$ and $\Delta L A I$ are discussed within the corresponding result Section 5.2.1. Backscattering varies with the dielectric and geometric properties of the soil-vegetation system. In particular, dielectric properties are ruled by $m_{\mathrm{v}}$ (for the soil layer) and canopy water content; whereas, the geometric properties are ruled by $h^{\prime}$ (for the soil layer) and by both vegetation biomass ( $F_{\mathrm{v}}$ and $\left.L A I\right)$ and canopy structure (this latter has not been parameterized during the campaign).

\subsubsection{Dynamic Analysis: Two Selected Plots}

This analysis was performed for two selected plots: the first displayed soil drying over both bare and vegetated stages (plot 460, sugar beet); the second (plot 450, barley) was fully vegetated from April to July, then, it was harvested and thus, was bare during the last two SAR acquisitions. The analysis allows understanding how $\sigma^{\circ}$ behaves with $m_{\mathrm{V}}$ over changing SVV. Outcomes over the first plot allow evaluating which channels have the higher sensitivity to vegetation growth. The dynamic of $\sigma^{\circ}$ over the second selected plot allows evaluating which channels have higher sensitivity to $m_{\mathrm{v}}$ when the soil is beneath a vegetation canopy.

\subsection{Temporal Single Regression Analysis}

Because of the speckle noise affecting SAR images at raw resolution, operational applications are to be preferred using spatially aggregated images by averaging both in situ measures and the corresponding aggregated $\sigma^{\circ}$ values. Thus, temporal single regressions among $\sigma^{\circ}$ and SVV were analyzed to address the application of semi-empirical models over bare and vegetated plots; $m_{\mathrm{V}}$ and $h^{\prime}$ were analyzed over bare soil, whereas, $F_{\mathrm{v}}$ and $L A I$ were also explored over vegetated areas.

\subsection{Inter-Channel Spatial/Temporal Correlation}

A target is expected exhibiting different dielectric and geometrical properties if sensed with distinct SAR configurations. Thus, a pixel based spatial correlation image, $r_{\mathrm{sp}}$, was evaluated for each plot using a moving kernel. A plot representative spatial correlation, $r_{\mathrm{s}}$, was obtained by averaging values of $r_{\mathrm{sp}}$ co-localized to in situ measures. The calculation is extended to all available channel pairs and acquisition times, thus, generating an $r_{\mathrm{s}}$ domain cube. Because the moving kernel is applied on spatially aggregated images, a minimum kernel size $(3 \times 3)$ was chosen to avoid exceeding plots' dimensions. A total of 45 channel pairs were analyzed; the $r_{\mathrm{s}}$ cube was evaluated for each of the 9 monitored plots.

The dynamic between $r_{\mathrm{s}}$ and SVV was analyzed via a single regression over 9 selected pairs of channels. The analysis determines in what extent $r_{\mathrm{S}}$ could be useful to assess SVV changes; thus, results are shown in terms of plot temporal correlation coefficients, $r_{\mathrm{t}}$, out-coming from the $r_{\mathrm{S}} \mathrm{vs}$. SVV regressions (Figure 4). 
Finally, errors associated to best regressions (both $\sigma^{\circ}$ vs. SVV and $r_{\mathrm{S}}$ vs. SVV) are computed in terms of mean absolute errors (MAE).

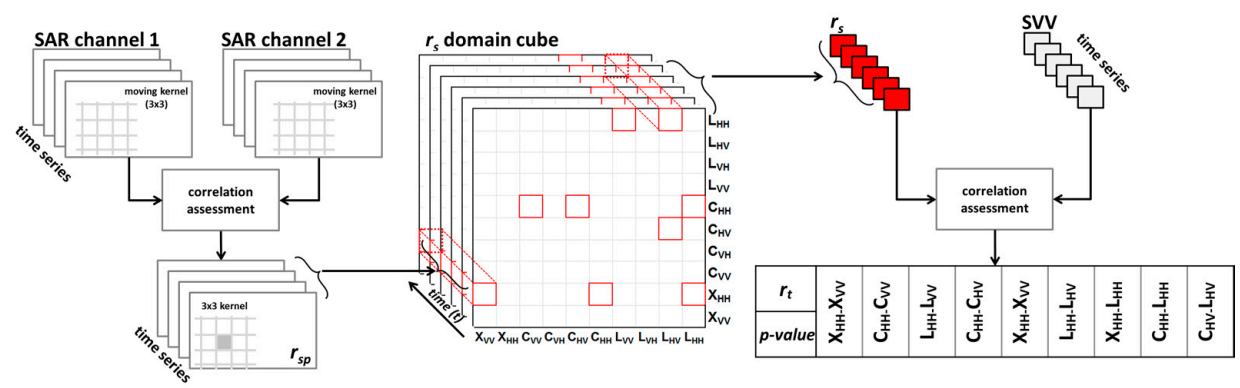

Figure 4. Flow-chart of the inter-channel spatial/temporal correlation analysis. The flow-chart is applied to each plot and for all four SVV $\left(m_{\mathrm{v}}, h^{\prime}, L A I\right.$ and $\left.F_{\mathrm{V}}\right)$. The 9 selected channel pairs are bounded in red within the $r_{\mathrm{S}}$ domain cube.

\section{Results}

\subsection{Data Aggregation}

The $I_{\mathrm{M}}$ first derivative suggests almost the same aggregation level for co-polarized, $\sigma^{\circ} \mathrm{pp}$, and cross-polarized, $\sigma_{\mathrm{pq}}^{\circ}$, channels. Whereas, $R_{\mathrm{S}}$ suggested by the $I_{\mathrm{S}}$ analysis are higher at $\sigma_{\mathrm{pp}}^{\circ}$ than those at $\sigma^{\circ}$ pq with highest values shown by $X_{\mathrm{HH}}$, and lowest value exhibited by $L_{\mathrm{HV}}$. The $R_{\mathrm{S}}$ equal to $20 \mathrm{~m}$, as suggested by $I_{\mathrm{S}}$ analysis, although even coarser then the value suggested by $I_{\mathrm{M}}$ analysis $(\approx 10 \mathrm{~m})$, remains suitable to characterize the average plot size $(\sim 280 \mathrm{~m})$.

\subsection{Dynamic Analyses}

\subsubsection{Dynamic Analysis: All Plots}

$\mathrm{L}$ bands show the highest $\Delta \sigma^{\circ}$ avg values especially at cross-polarized channels. This suggests that $\sigma^{\circ}$ at $\mathrm{L}$ band could be highly influenced by SVV dynamics. The higher values of $\Delta \sigma^{\circ}$ stdev also highlight that $\sigma^{\circ}$ is influenced by SVV depending on the cultivar; contrarily, lower $\Delta \sigma^{\circ}$ stdev exhibited by $X_{p p}$ and $C_{p p}$ bands implies a weaker influence of the cultivar (Figure 5 , left panel).
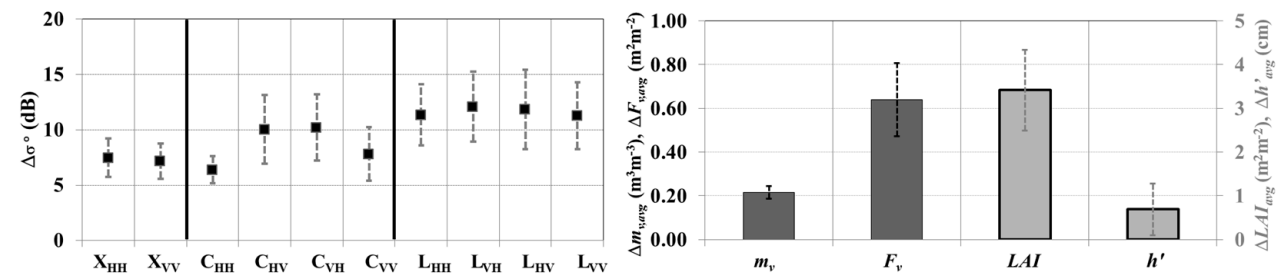

Figure 5. Observed $\Delta \sigma^{\circ}$ avg and corresponding $\Delta \sigma^{\circ}$ stdev (dashed lines) for all available channels are shown on the left panel; $\Delta m_{\mathrm{v}, \text { avg }}, \Delta F_{\mathrm{v}, \text { avg }}$ (dark-grey vertical bars, primary axis), $\Delta L A I_{\mathrm{avg}}$ and $\Delta h^{\prime}{ }_{\text {avg }}$ (bright-grey vertical bars, secondary axis), and corresponding $\Delta \mathrm{SSV}_{\text {stdev }}$ (dashed lines) are shown on the right panel.

Numerically, the highest dynamic $\left(\Delta \sigma^{\circ}\right.$ avg $=12 \mathrm{~dB}$ and $\left.\Delta \sigma_{\text {stdev }}^{\circ}=3.2 \mathrm{~dB}\right)$ is exhibited by $\mathrm{L}_{\mathrm{HV}}$ whereas the lowest is observed for $C_{\mathrm{HH}}\left(\Delta \sigma^{\circ}\right.$ avg $=6.4 \mathrm{~dB}$ and $\left.\Delta \sigma^{\circ}{ }_{\text {stdev }}=1.2 \mathrm{~dB}\right)$. SVV variations are responsible of changes of dielectric and geometric properties of the soil-vegetation system (Figure 5, right panel). The variations of $m_{\mathrm{v}}$ was on average $\approx 0.2 \mathrm{~m}^{3} \mathrm{~m}^{-3}$ (with standard deviation $\left.\Delta m_{\mathrm{v}, \text { stdev }}=0.03 \mathrm{~m}^{3} \mathrm{~m}^{-3}\right)$, whereas $\Delta F_{\mathrm{v}, \text { avg }}=0.64\left(\Delta F_{\mathrm{v}, \text { stdev }}=0.17\right), \Delta L A I_{\mathrm{avg}}=3.42 \mathrm{~m}^{3} \mathrm{~m}^{-2}$ $\left(\Delta L A I_{\text {stdev }}=0.92 \mathrm{~m}^{3} \mathrm{~m}^{-2}\right)$ and $\Delta h_{\text {avg }}^{\prime}=0.7 \mathrm{~cm}\left(\Delta h_{\text {stdev }}^{\prime}=0.6 \mathrm{~cm}\right)$. To describe the differences observed 
in distinct channels as resulting from SVV changes, the dynamic analysis was applied to bare plots (plots 460 and 222).

Bare soils exhibited lower $\Delta \sigma^{\circ}$ avg (particularly at $L$ frequency) compared with those observable during the whole investigation period (where both bare and vegetated conditions occurred).

Over vegetation, the highest $\Delta \sigma^{\circ}$ avg at $L$ frequency was found for sugar beet, which is characterized by a broad-leaf structure; whereas $X$ channels exhibited highest $\Delta \sigma^{\circ}$ avg for barley and wheat; finally $C$ channels exhibited highest $\Delta \sigma^{\circ}$ avg for rape, barley and wheat. These differences confirm that vegetation structure determines the geometric properties of the target.

\subsubsection{Dynamic Analysis: Two Selected Plots}

The dynamic analysis for the plot 460 revealed that $\sigma^{\circ}$ pq exhibits lower values if compared to $\sigma_{\mathrm{pp}}^{\circ}$ at the same frequency. Peaks of $\sigma^{\circ}$ occur contextually to $m_{\mathrm{v}}$ maxima (Figure 6 , drying period I). As expected, $\sigma^{\circ}$ over bare soil (until the 11th of May) is linearly correlated to $m_{\mathrm{v}}$ at all channels. With the growth of the vegetation two different $\sigma^{\circ}$ behaviors were observed: $\sigma^{\circ}$ at $L$ (both $\sigma^{\circ}$ pp and $\left.\sigma_{\mathrm{pq}}^{\circ}\right)$ and $\mathrm{C}\left(\sigma_{\mathrm{pq}}^{\circ}\right.$ only) is highly related to $m_{\mathrm{v}}$ until $F_{\mathrm{v}}$ is lower than $3 \%$. Whereas $\sigma_{\mathrm{pp}}^{\circ}$ at $\mathrm{X}$ and $\mathrm{C}$ frequencies were still influenced by $m_{\mathrm{v}}$ dynamics until $F_{\mathrm{V}}$ is lower than $10 \%$ (Figure 6, drying period II).
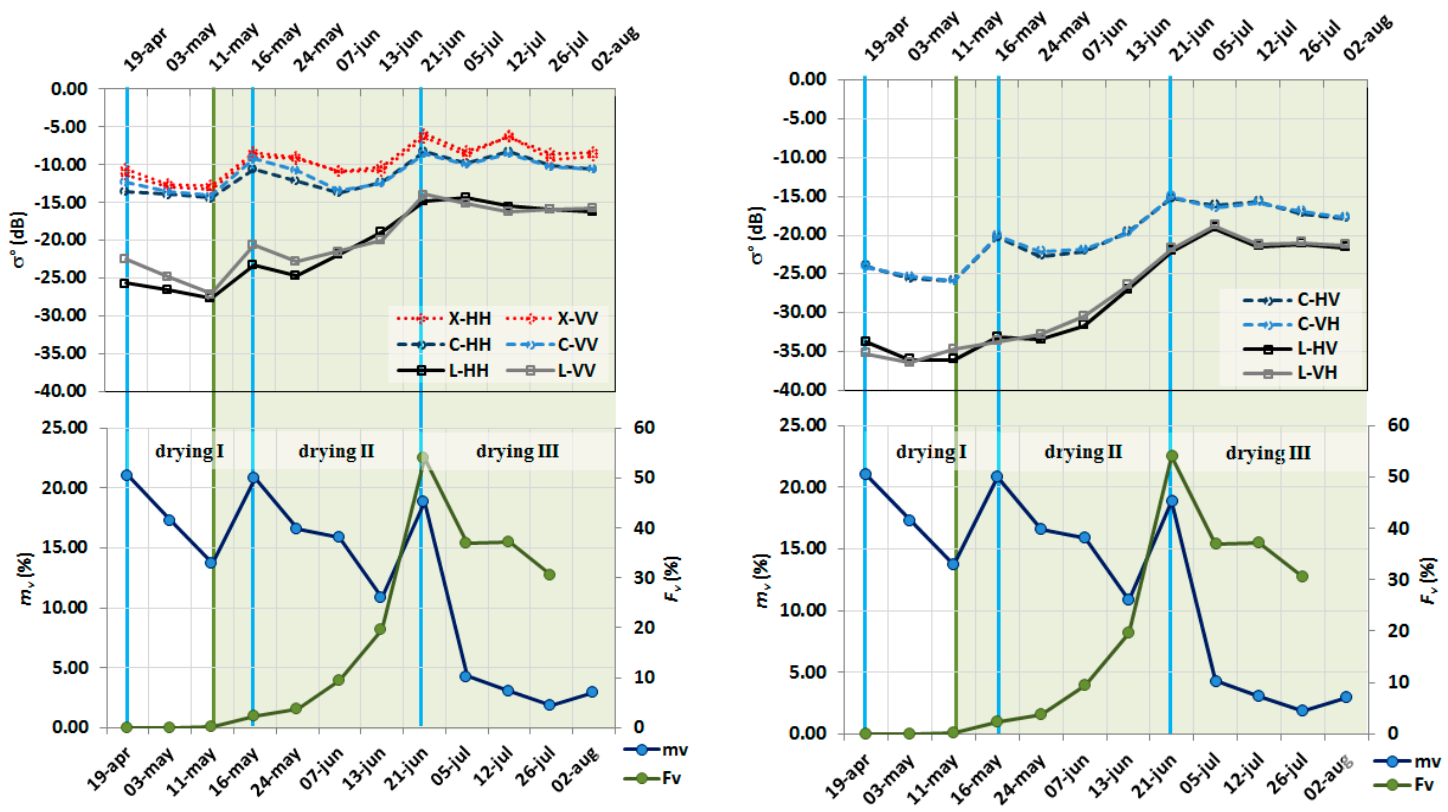

Figure 6. SVV $\left(m_{\mathrm{v}}\right.$ and $\left.F_{\mathrm{V}}\right)$ and $\sigma^{\circ}$ temporal dynamics for the plot 460 (sugar beet); co-polarized $\sigma^{\circ}$ are shown in the upper left panel, whereas cross-polarized $\sigma^{\circ}$ are in the upper right panel. Vertical blue bars mark $m_{\mathrm{v}}$ peaks separating three consecutive drying periods; the green vertical bar marks the time in which the increase of $F_{\mathrm{v}}$ began.

The difference between $\sigma^{\circ}$ collected on 19 April and 21 June is prevalently a measure of the vegetation biomass change; indeed, $\sigma^{\circ}$ at these two times were acquired at almost similar $h^{\prime}$ and $m_{\mathrm{V}}$ conditions. It is noticeable that high positive $\sigma^{\circ}$ differences occur at cross-polarization, thus confirming outcomes of several other studies (e.g., [56]).

The dynamic analysis for the plot 450 (barley) revealed that all $\sigma^{\circ}$ at $\mathrm{L}$ frequency behave similarly to $m_{\mathrm{v}} ; \sigma^{\circ}$ at $\mathrm{C}$ and $\mathrm{X}$ frequencies is less influenced by $m_{\mathrm{v}}$ dynamics, thus highlighting that $\sigma^{\circ}$ at L frequency partially penetrated the canopy cover (Figure 7, drying periods I to III). In particular, $\sigma^{\circ}$ L,HH vs. $m_{\mathrm{V}}$ was characterized by $r^{2} \approx 0.27$, whereas lower $r^{2}$ characterized regressions with other frequencies $\left(r^{2} \sim 10^{-4}\right.$ for both $\sigma^{\circ} \mathrm{C}, \mathrm{HH}$ and $\sigma^{\circ} \mathrm{X}, \mathrm{HH}$ vs. $\left.m_{\mathrm{v}}\right)$. Conversely, $\mathrm{L}$ frequencies were not linked 
to $F_{\mathrm{V}}\left(r^{2} \sim 0.05\right)$; whereas, slightly higher $r^{2}(\sim 0.15)$ characterized $\sigma^{\circ}$ vs. $F_{\mathrm{v}}$ at $\mathrm{C}$ frequency; finally, $\mathrm{X}$ channels were completely uncorrelated with $F_{\mathrm{V}}\left(r^{2} \sim 10^{-6}\right)$.
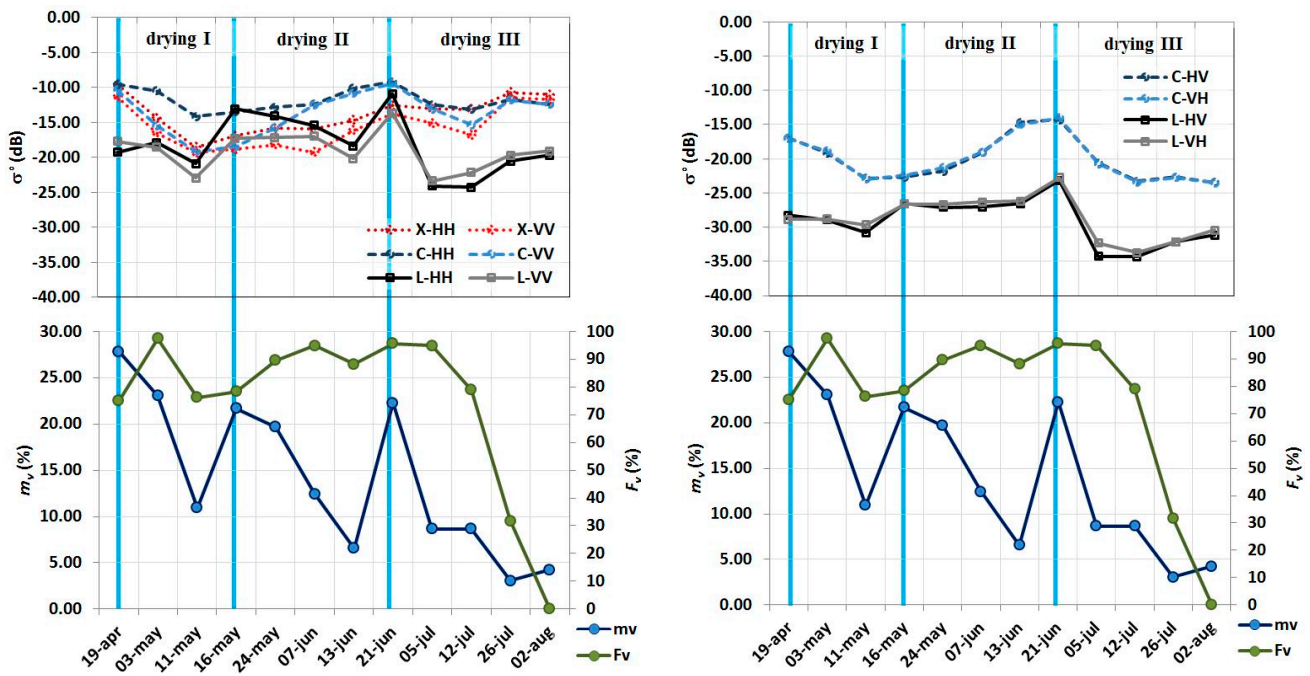

Figure 7. SVV $\left(m_{\mathrm{v}}\right.$ and $\left.F_{\mathrm{v}}\right)$ and $\sigma^{\circ}$ temporal dynamics for the plot 450 (barley); co-polarized $\sigma^{\circ}$ are shown in the upper left panel, whereas cross-polarized $\sigma^{\circ}$ are in the upper right panel. Vertical blue bars mark $m_{\mathrm{v}}$ peaks separating three consecutive drying periods.

\subsection{Temporal Single Regression Analysis}

A first analysis was applied on bare soils having different $h^{\prime}$. Single regressions among $\sigma^{\circ}$ vs. $m_{\mathrm{v}}$ and $h^{\prime}$ were calculated separately for two plots (IDs 460 and 222) that remained bare until the first week of May; $h^{\prime}$ values ranged between $0.93-1.77$ and 1.42-2.05 cm, for plots 460 and 222 respectively (Table 3). Correlations, $r$, are classified according to Evans, 1996 [57]; slopes, $m$, and intercepts, $q$, values could be employed to apply empirical or semi-empirical models (e.g., the WC model [17]). No significant correlations characterized the $\sigma^{\circ}$ vs. $h^{\prime}$ regressions (not shown).

Table 3. $\sigma^{\circ}$ vs. $m_{\mathrm{v}}$ over bare soil for plot 460 (left panel) and plot 222 (right panel). Significant and very strong correlations (i.e., $p$-value less than 0.05 and $r>0.8$ ) are highlighted in dark-grey with values in bold: quasi-significant correlations (i.e., $0.05<p$-value $<0.1$ ) are underlined.

\begin{tabular}{cccccccccc}
\hline $\boldsymbol{\sigma}^{\circ}$ vs. $\boldsymbol{m}_{\mathbf{v}}$ & $\boldsymbol{r}$ & $\boldsymbol{m}$ & $\boldsymbol{q}$ & $\boldsymbol{p}$-Value & $\boldsymbol{\sigma}^{\circ}$ vs. $\boldsymbol{m}_{\mathbf{v}}$ & $\boldsymbol{r}$ & $\boldsymbol{m}$ & $\boldsymbol{q}$ & $\boldsymbol{p}$-Value \\
\hline $\mathbf{X}_{\mathbf{H H}}$ & $\underline{0.79}$ & $\underline{1.00}$ & $\underline{-30.12}$ & $\underline{6.0 \times 10^{-2}}$ & $\mathbf{X}_{\mathbf{H H}}$ & 0.62 & 0.46 & -22.89 & $2.6 \times 10^{-1}$ \\
$\mathbf{X}_{\mathbf{V V}}$ & $\mathbf{0 . 8 3}$ & $\mathbf{1 . 0 1}$ & -29.98 & $\mathbf{4 . 0 \times 1 0 ^ { - 2 }}$ & $\mathbf{X}_{\mathbf{V V}}$ & 0.61 & 0.43 & -22.40 & $2.8 \times 10^{-1}$ \\
$\mathbf{C}_{\mathbf{H H}}$ & 0.60 & 0.59 & -24.29 & $2.1 \times 10^{-1}$ & $\mathbf{C}_{\mathbf{H H}}$ & $\mathbf{0 . 8 3}$ & $\mathbf{0 . 5 6}$ & $-\mathbf{2 5 . 7 9}$ & $\mathbf{8 . 0} \times \mathbf{1 0}^{-2}$ \\
$\mathbf{C}_{\mathbf{H V}}$ & 0.63 & 0.94 & -41.30 & $1.8 \times 10^{-1}$ & $\mathbf{C}_{\mathbf{H V}}$ & 0.71 & 0.54 & -34.42 & $1.8 \times 10^{-1}$ \\
$\mathbf{C}_{\mathbf{V V}}$ & 0.71 & 0.91 & -29.61 & $1.2 \times 10^{-1}$ & $\mathbf{C}_{\mathbf{V V}}$ & 0.77 & 0.52 & -24.14 & $1.3 \times 10^{-1}$ \\
$\mathbf{L}_{\mathbf{H H}}$ & 0.46 & 0.67 & -37.84 & $3.6 \times 10^{-1}$ & $\mathbf{L}_{\mathbf{H H}}$ & $\mathbf{0 . 9 9}$ & $\mathbf{1 . 1 2}$ & $-\mathbf{5 1 . 4 5}$ & $\mathbf{6 . 2} \times \mathbf{1 0}^{-4}$ \\
$\mathbf{L}_{\mathbf{H V}}$ & 0.65 & 0.78 & -48.88 & $1.6 \times 10^{-1}$ & $\mathbf{L}_{\mathbf{H V}}$ & $\mathbf{0 . 9 9}$ & $\mathbf{0 . 9 8}$ & $-\mathbf{5 4 . 9 9}$ & $\mathbf{2 . 8} \times \mathbf{1 0}^{-4}$ \\
$\mathbf{L}_{\mathbf{V V}}$ & $\underline{0.74}$ & $\underline{1.20}$ & $\underline{-46.16}$ & $\underline{9.6 \times 10^{-2}}$ & $\mathbf{L} \mathbf{V V}$ & $\mathbf{0 . 9 9}$ & $\mathbf{1 . 3 4}$ & $-\mathbf{5 6 . 5 9}$ & $\mathbf{4 . 2} \times \mathbf{1 0}^{-4}$ \\
\hline
\end{tabular}

Noticeable, very strong and significant $\sigma^{\circ}$ vs. $m_{\mathrm{v}}$ correlations were found for $\mathrm{X}_{\mathrm{VV}}$ (plot 460 ), $\mathrm{C}_{\mathrm{HH}}$ and for L frequencies (plot 222); while, strong (i.e., $0.6<r<0.8$ ) correlations were not significant ( $p$-value $>0.1)$.

For plot 460 two quasi-significant correlations were found at $\mathrm{X}_{\mathrm{HH}}$ and $\mathrm{LVV}_{\mathrm{VV}}$, respectively. The highest $\sigma^{\circ}$ vs. $m_{\mathrm{v}}$ correlations were found at L frequency $(\approx 0.99)$.

A second analysis was applied on vegetated plots (Table 4). Noticeable, $\sigma^{\circ}$ vs. $h^{\prime}$ returned no significant correlations (not shown). Regarding $\sigma^{\circ}$ vs. $m_{\mathrm{v}}$, only moderate to strong correlations $(0.4<r<0.8)$ were found as the capability of the signal of perceiving the $m_{\mathrm{v}}$ is attenuated by the 
vegetation cover. Most significant $\sigma^{\circ}$ vs. $m_{\mathrm{v}}$ correlations were found at $L$ frequency, highlighting that the longer the wave the better the canopy penetration. A limited number of quasi- and significant correlations were found at $C$ and $X$ frequencies even if these were characterized by lower $r$ values.

Table 4. $\quad r$ of $\sigma^{\circ}$ vs. $m_{\mathrm{v}}$ for plots covered by vegetation. Quasi-significant correlations (i.e., $0.05<p$-value $<0.1$ ) are outlined; significant correlations (i.e., $p$-value $<0.05$ ) are highlighted in light-grey; strong and significant correlations are also bolded; very weak correlations $(r<0.19)$ are not reported.

\begin{tabular}{ccccccccccc}
\hline \multirow{2}{*}{$\boldsymbol{\sigma}^{\circ}$ vs. $\boldsymbol{m}_{\mathbf{v}}$} & \multicolumn{2}{c}{ Sugar } & \multicolumn{2}{c}{ Barley } & \multicolumn{2}{c}{ Maize } & \multicolumn{2}{c}{ Rape } & \multicolumn{2}{c}{ Wheat } \\
\cline { 2 - 10 } & $\boldsymbol{r}$ & $\boldsymbol{p}$-Value & $\boldsymbol{r}$ & $\boldsymbol{p}$-Value & $\boldsymbol{r}$ & $\boldsymbol{p}$-Value & $\boldsymbol{r}$ & $\boldsymbol{p}$-Value & $\boldsymbol{r}$-Value \\
\hline $\mathbf{X}_{\mathbf{H H}}$ & 0.32 & $5.9 \times 10^{-1}$ & - & - & 0.54 & $2.7 \times 10^{-1}$ & $\underline{0.37}$ & $\underline{8.4 \times 10^{-2}}$ & 0.25 & $2.6 \times 10^{-1}$ \\
$\mathbf{X}_{\mathbf{V V}}$ & 0.34 & $5.7 \times 10^{-1}$ & - & - & 0.55 & $2.6 \times 10^{-1}$ & 0.46 & $2.7 \times 10^{-2}$ & - & - \\
$\mathbf{C}_{\mathbf{H H}}$ & 0.23 & $7.2 \times 10^{-1}$ & $\underline{0.38}$ & $\underline{7.4 \times 10^{-2}}$ & 0.39 & $4.4 \times 10^{-1}$ & 0.19 & $4.0 \times 10^{-1}$ & 0.32 & $1.3 \times 10^{-1}$ \\
$\mathbf{C}_{\mathbf{H V}}$ & - & - & $\underline{0.35}$ & $\underline{9.8 \times 10^{-2}}$ & - & - & - & - & 0.46 & $2.6 \times 10^{-2}$ \\
$\mathbf{C}_{\mathbf{V V}}$ & - & - & - & - & 0.59 & $2.1 \times 10^{-1}$ & 0.27 & $2.1 \times 10^{-1}$ & - & - \\
$\mathbf{L}_{\mathbf{H H}}$ & - & - & 0.46 & $2.8 \times 10^{-2}$ & $\underline{0.75}$ & $\underline{8.4 \times 10^{-2}}$ & 0.46 & $2.6 \times 10^{-2}$ & 0.51 & $1.3 \times 10^{-2}$ \\
$\mathbf{L}_{\mathbf{H V}}$ & -0.52 & $3.7 \times 10^{-1}$ & 0.52 & $1.2 \times 10^{-2}$ & 0.72 & $1.1 \times 10^{-1}$ & $\underline{0.39}$ & $\underline{6.6 \times 10^{-2}}$ & $\mathbf{0 . 6 6}$ & $\mathbf{6 . 6} \times \mathbf{1 0}^{-\mathbf{4}}$ \\
$\mathbf{L}_{\mathbf{V V}}$ & - & - & 0.53 & $9.4 \times 10^{-3}$ & 0.28 & $5.9 \times 10^{-1}$ & 0.40 & $5.0 \times 10^{-2}$ & 0.55 & $7.0 \times 10^{-3}$ \\
\hline
\end{tabular}

Several very strong and significant $\sigma^{\circ}$ vs. $F_{\mathrm{v}}$ correlations (Table 5) were found over maize (at $\mathrm{C}_{\mathrm{HV}}$, $\mathrm{L}_{\mathrm{HH}}$ and $\mathrm{L}_{\mathrm{HV}}$ ) and sugar (all channels except $\mathrm{L}_{\mathrm{HH}}$ and $\mathrm{L}_{\mathrm{HV}}$ ). These plants are both characterized by bigger leaf dimensions compared to those characterizing other cultivars. Noticeable, $\sigma^{\circ}$ vs. $F_{\mathrm{v}}$ regressions showed higher $r$ than those characterizing $\sigma^{\circ}$ vs. $m_{\mathrm{V}}$ (best $r \sim 0.95$ for $\sigma^{\circ}$ vs. $F_{\mathrm{V}}$ at $\mathrm{L}_{\mathrm{HV}}$ over maize plot), thus confirming that: (i) $\sigma^{\circ}$ is mainly controlled by geometric and dielectric properties of the vegetation; (ii) the canopy limits the assessment of the properties of the underlying soil. Although several significant correlations were found for other cultivars, these were characterized by weak $(0.2<r<0.4)$ or moderate $(0.4<r<0.6) r$ values.

Table 5. $r$ of $\sigma^{\circ}$ vs. $F_{\mathrm{v}}$ for plots covered by vegetation. Quasi-significant correlations are outlined; significant correlations are highlighted in light-grey; very strong and significant correlations are highlighted in dark-gray with values in bold; very weak correlations are not reported.

\begin{tabular}{|c|c|c|c|c|c|c|c|c|c|c|}
\hline \multirow{2}{*}{$\sigma^{\circ}$ vs. $F_{\mathbf{v}}$} & \multicolumn{2}{|c|}{ Sugar } & \multicolumn{2}{|c|}{ Barley } & \multicolumn{2}{|c|}{ Maize } & \multicolumn{2}{|c|}{ Rape } & \multicolumn{2}{|c|}{ Wheat } \\
\hline & $r$ & $p$-Value & $r$ & $p$-Value & $r$ & $p$-Value & $r$ & $p$-Value & $r$ & $p$-Value \\
\hline $\mathrm{X}_{\mathrm{HH}}$ & 0.90 & $3.8 \times 10^{-2}$ & 0.19 & $3.9 \times 10^{-1}$ & 0.30 & $6.3 \times 10^{-1}$ & $\underline{0.39}$ & $7.2 \times 10^{-2}$ & - & - \\
\hline$X_{V V}$ & $\underline{0.85}$ & $7.0 \times 10^{-2}$ & 0.27 & $2.2 \times 10^{-1}$ & 0.22 & $7.3 \times 10^{-1}$ & $\overline{0.32}$ & $\overline{1.5 \times 10^{-1}}$ & - & - \\
\hline $\mathrm{C}_{\mathrm{HH}}$ & $\overline{0.87}$ & $5.0 \times 10^{-2}$ & - & - & 0.52 & $3.7 \times 10^{-1}$ & 0.33 & $1.3 \times 10^{-1}$ & - & - \\
\hline $\mathrm{C}_{\mathrm{HV}}$ & 0.90 & $3.7 \times 10^{-2}$ & - & - & $\underline{0.81}$ & $9.6 \times 10^{-2}$ & - & - & - & - \\
\hline $\mathrm{C}_{\mathrm{VV}}$ & $\underline{0.87}$ & $5.8 \times 10^{-2}$ & - & - & $\overline{0.21}$ & $\overline{7.3 \times 10^{-1}}$ & $\underline{0.37}$ & $9.3 \times 10^{-2}$ & 0.29 & $1.9 \times 10^{-1}$ \\
\hline $\mathrm{L}_{\mathrm{HH}}$ & $\overline{0.79}$ & $\overline{1.1 \times 10^{-1}}$ & - & - & 0.87 & $5.0 \times 10^{-2}$ & $\overline{0.39}$ & $\overline{7.6 \times 10^{-2}}$ & 0.28 & $2.1 \times 10^{-1}$ \\
\hline $\mathbf{L}_{\mathrm{HV}}$ & 0.53 & $3.6 \times 10^{-1}$ & - & - & 0.95 & $1.2 \times 10^{-2}$ & $\overline{0.48}$ & $\overline{2.3 \times 10^{-2}}$ & 0.33 & $1.3 \times 10^{-1}$ \\
\hline LVV & 0.90 & $3.9 \times 10^{-2}$ & - & - & 0.69 & $1.9 \times 10^{-1}$ & 0.54 & $9.3 \times 10^{-3}$ & - & - \\
\hline
\end{tabular}

The highest and significant $\sigma^{\circ}$ vs. $L A I$ correlations were found again for sugar beet and maize; whereas, no significant correlations were found at $\mathrm{X}$ and $\mathrm{C}_{\mathrm{HH}}$ channels. Several significant correlations were found for other cultivars; diversely than $\sigma^{\circ}$ vs. $F_{\mathrm{v}}$, most of these exhibited a strong correlation (Table 6). For some channels, $\sigma^{\circ}$ resulted significantly correlated with both $L A I$ and $F_{\mathrm{v}}$. Although $\sigma^{\circ}$ at $\mathrm{L}_{\mathrm{HH}}$ resulted also correlated to $m_{\mathrm{v}}$ the higher $p$-value indicates a weaker significance of this correlation. 
Table 6. $r$ of $\sigma^{\circ}$ vs. $L A I$ for plots covered by vegetation. Significant correlations are highlighted in light-grey; strong and significant correlations are also bolded; very strong and significant correlations are highlighted in dark-grey with values in bold; very weak correlations are not reported.

\begin{tabular}{|c|c|c|c|c|c|c|c|c|c|c|}
\hline \multirow{2}{*}{$\begin{array}{c}\sigma^{\circ} \text { vs. } \\
L A I\end{array}$} & \multicolumn{2}{|r|}{ Sugar } & \multicolumn{2}{|c|}{ Barley } & \multicolumn{2}{|c|}{ Maize } & \multicolumn{2}{|c|}{ Rape } & \multicolumn{2}{|c|}{ Wheat } \\
\hline & $r$ & $p$-Value & $r$ & $p$-Value & $r$ & $p$-Value & $r$ & $p$-Value & $r$ & $p$-Value \\
\hline $\mathrm{X}_{\mathrm{HH}}$ & 0.72 & 0.17 & 0.63 & $4.7 \times 10^{-3}$ & - & - & - & - & 0.50 & $2.5 \times 10^{-2}$ \\
\hline $\mathrm{X}_{\mathrm{VV}}$ & 0.70 & 0.19 & 0.61 & $6.7 \times 10^{-3}$ & - & - & - & - & 0.51 & $2.2 \times 10^{-2}$ \\
\hline $\mathrm{C}_{\mathrm{HH}}$ & 0.80 & $1.0 \times 10^{-1}$ & 0.32 & $1.9 \times 10^{-1}$ & 0.31 & $6.2 \times 10^{-1}$ & 0.31 & $1.8 \times 10^{-1}$ & 0.64 & $2.4 \times 10^{-3}$ \\
\hline $\mathrm{C}_{\mathrm{HV}}$ & 0.91 & $3.1 \times 10^{-2}$ & - & - & 0.64 & $2.5 \times 10^{-1}$ & - & - & 0.49 & $2.7 \times 10^{-2}$ \\
\hline $\mathrm{C}_{\mathrm{VV}}$ & 0.80 & $1.0 \times 10^{-1}$ & 0.19 & $4.5 \times 10^{-1}$ & - & - & 0.21 & $3.8 \times 10^{-1}$ & 0.19 & $4.3 \times 10^{-1}$ \\
\hline $\mathrm{L}_{\mathrm{HH}}$ & 0.98 & $2.7 \times 10^{-3}$ & 0.53 & $2.2 \times 10^{-2}$ & 0.94 & $1.9 \times 10^{-2}$ & 0.44 & $5.0 \times 10^{-2}$ & 0.38 & $9.8 \times 10^{-2}$ \\
\hline $\mathrm{L}_{\mathrm{HV}}$ & 0.93 & $2.1 \times 10^{-2}$ & 0.60 & $7.9 \times 10^{-3}$ & 0.95 & $1.2 \times 10^{-2}$ & 0.60 & $4.7 \times 10^{-3}$ & 0.25 & $3.0 \times 10^{-1}$ \\
\hline LVV & 0.89 & $4.5 \times 10^{-2}$ & 0.32 & $1.9 \times 10^{-1}$ & 0.59 & $2.9 \times 10^{-1}$ & 0.28 & $2.3 \times 10^{-1}$ & - & - \\
\hline
\end{tabular}

\subsection{Inter-Channel Spatial/Temporal Correlation at Plot Scale}

This section discusses and analyzes $r_{\mathrm{S}}$ domains for the two selected plots (see Sections 4.2.2 and 5.2.2). For the plot 460, $r_{\mathrm{s}}$ domains were analyzed for increasing vegetation cover (for bare to vegetated) and decreasing $m_{\mathrm{v}}$ (Figure 8). In particular, three different dates were selected: (i) 19 April, when field was bare and $m_{\mathrm{v}} \sim 0.21 \mathrm{~m}^{3} \mathrm{~m}^{-3}$; (ii) 7 June, when field was slightly vegetated $\left(F_{\mathrm{v}} \sim 0.1\right)$ and $m_{\mathrm{v}}$ decreased to $\sim 0.16 \mathrm{~m}^{3} \mathrm{~m}^{-3}$; and, (iii) 26 July, when $F_{\mathrm{v}}$ increased up to $(\sim 0.35)$ and the $m_{\mathrm{v}}$ decreased to $\sim 0.02 \mathrm{~m}^{3} \mathrm{~m}^{-3}$.
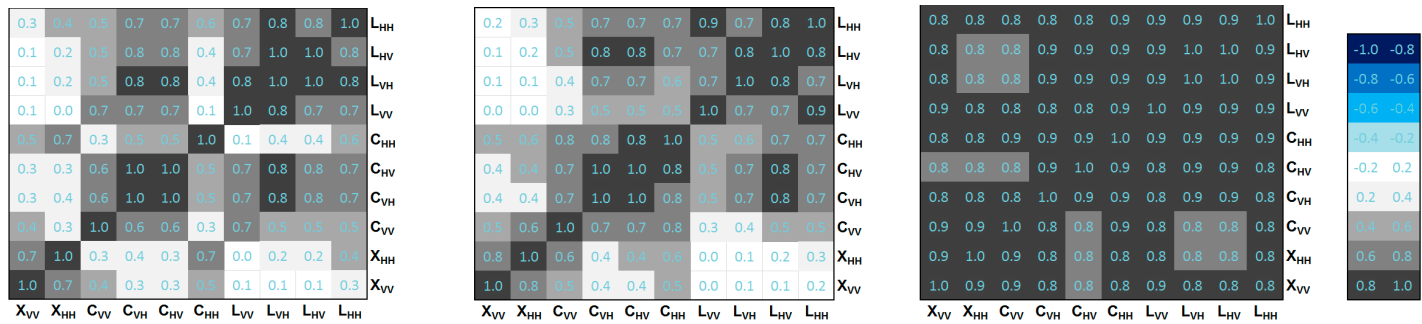

Figure 8. $r_{\mathrm{s}}$ domain for plot 460 at three selected dates: 19 April (left panel), 7 June (central panel) and 26 July (right panel). The dichromatic color ramp describes very strong negative to very strong positive correlations (from blue to grey). Values of $r_{\mathrm{s}}$ rounded to first decimal place are also reported.

On 19 April the $r_{\mathrm{S}}$ domain highlights that strong to very strong correlation occurred among $\sigma^{\circ}$ at $\mathrm{L}$ and $\mathrm{X}$ channels, weak to very strong correlations were observed among $\sigma^{\circ}$ at $\mathrm{C}$ channels. On 7 June, when $m_{\mathrm{V}}$ slightly decreased and sugar beet started growing $\left(F_{\mathrm{V}} \sim 0.1\right) ; r_{\mathrm{s}}$ between $\sigma^{\circ}$ at some channels slightly increased (e.g., $\sigma^{\circ}$ at $\mathrm{C}_{\mathrm{HH}}$ and $\mathrm{C}_{\mathrm{VV}}$ ). Finally, on the 26th of July $\sigma^{\circ}$ of most of the bands were strongly correlated $\left(r_{\mathrm{s}}>0.8\right)$. Whereas, lower correlations were observed among some $\sigma^{\circ}$ at $\mathrm{C}_{\mathrm{HV}}$ and $\sigma_{\mathrm{pq}}^{\circ}$ at $\mathrm{L}$ frequency $\left(r_{\mathrm{s}} \sim 0.8\right)$. The decreasing of $m_{\mathrm{v}}$ caused a noticeable increasing of $r_{\mathrm{s}}$ for all channel pairs.

For the field 450 (Figure 9) $r_{\mathrm{s}}$ domains were analyzed at three selected times: (i) on 13 June, when $F_{\mathrm{V}} \sim 0.9$ and $m_{\mathrm{V}} \sim 0.06 \mathrm{~m}^{3} \mathrm{~m}^{-3}$; (ii) on 21 June, when $F_{\mathrm{v}}$ slightly increased $\left(F_{\mathrm{V}} \sim 0.95\right)$ and $m_{\mathrm{V}}$ considerably increased to $\sim 0.22 \mathrm{~m}^{3} \mathrm{~m}^{-3}$; and, (iii) on 26 July, when both $F_{\mathrm{V}}$ and $m_{\mathrm{V}}$ considerably decreased to $\sim 0.3$ and $\sim 0.06 \mathrm{~m}^{3} \mathrm{~m}^{-3}$ respectively. 

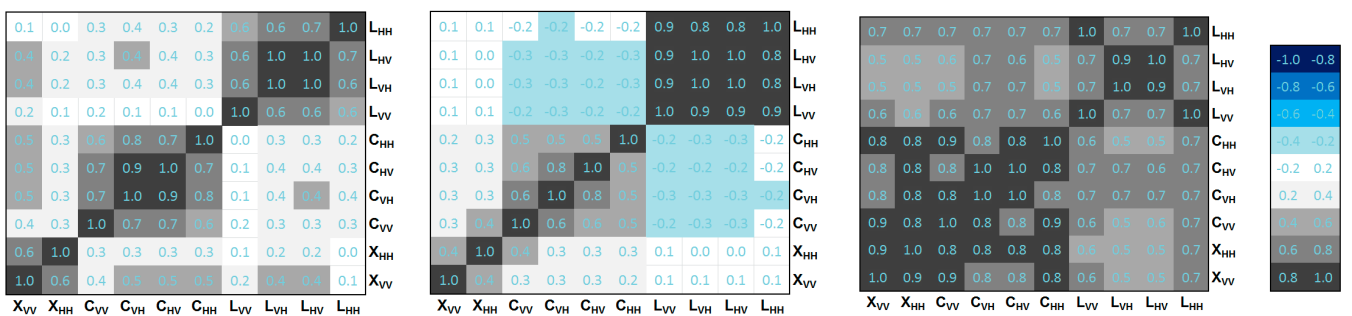

Figure 9. $r_{\mathrm{s}}$ domain for plot 450 three selected times: 13 June (left panel); 21 June (center panel) and 26 July (right panel). The dichromatic color ramp describes very strong negative to very strong positive correlations (from blue to grey). Values of $r_{\mathrm{s}}$ rounded to first decimal place are also reported.

On 13 June, the higher correlations among channels of the same frequency are observable. More specifically, moderate to very strong correlations occur among X, C and L frequency channels. Conversely, very weak to weak correlations characterized inter-frequency channels (e.g., $C$ vs. $\mathrm{L}$ frequencies). On 21 June, $m_{\mathrm{v}}$ considerably increased (with almost constant $F_{\mathrm{V}}$ ) causing a radical change in the $C$ vs. L region; indeed, positive weak became negative weak correlations. On 26 July the $m_{\mathrm{V}}$ and $F_{\mathrm{V}}$ decreased to their minimum values causing the considerably increase of all $r_{\mathrm{s}}$ values.

Based on the above mentioned evidences, it could be hypnotized that $r_{\mathrm{S}}$ and SVV time series are correlated (temporal).

Thus, for 9 selected channel pairs the $r_{\mathrm{s}}$ vs. SVV were computed over both bare soil (Table 7) and vegetated plots (Tables 8-11) to explore the determinability of SVV through $r_{\mathrm{s}}$. Results are shown in terms of correlation coefficients, $r_{\mathrm{t}}$.

Table 7. $r_{\mathrm{t}}$, over bare soils occurring during the study period; quasi-significant correlations (i.e., characterized by $0.05<p$-value $<0.1)$ are outlined; very weak correlations $(r<0.19)$ are not reported.

\begin{tabular}{|c|c|c|c|c|c|c|c|c|}
\hline \multirow{4}{*}{$r_{\mathrm{s}}$} & \multicolumn{8}{|c|}{$r_{\mathrm{t}}(-)$} \\
\hline & \multicolumn{4}{|c|}{$r_{\mathrm{s}}$ vs. $m_{\mathrm{v}}$} & \multicolumn{4}{|c|}{$r_{\mathrm{s}}$ vs. $h^{\prime}$} \\
\hline & \multicolumn{2}{|c|}{ Sugar Crop } & \multicolumn{2}{|c|}{ Maize Crop } & \multicolumn{2}{|c|}{ Sugar Crop } & \multicolumn{2}{|c|}{ Maize Crop } \\
\hline & $r$ & $p$-Value & $r$ & $p$-Value & $r$ & $p$-Value & $r$ & $p$-Value \\
\hline$\sigma^{\circ} \mathrm{X}, \mathrm{HH}$ vs. $\sigma^{\circ} \mathrm{X}, \mathrm{VV}$ & -0.22 & $7.2 \times 10^{-1}$ & 0.65 & $2.4 \times 10^{-1}$ & 0.88 & $5.1 \times 10^{-2}$ & - & - \\
\hline$\sigma^{\circ}{ }_{C, H H}$ vs. $\sigma^{\circ}{ }_{C, V V}$ & -0.57 & $3.2 \times 10^{-1}$ & -0.51 & $3.8 \times 10^{-1}$ & $\overline{0.65}$ & $\overline{2.4 \times 10^{-1}}$ & 0.29 & $7.1 \times 10^{-1}$ \\
\hline$\sigma^{\circ}{ }_{L, H H}$ vs. $\sigma^{\circ}{ }_{L, V V}$ & -0.64 & $2.5 \times 10^{-1}$ & -0.66 & $2.2 \times 10^{-1}$ & 0.56 & $3.2 \times 10^{-1}$ & - & - \\
\hline$\sigma^{\circ}{ }_{\mathrm{C}, \mathrm{HH}}$ vs. $\sigma^{\circ}{ }_{\mathrm{C}, \mathrm{HV}}$ & -0.33 & $5.9 \times 10^{-1}$ & - & - & -0.62 & $2.6 \times 10^{-1}$ & - & - \\
\hline$\sigma^{\circ}{ }_{L, H H}$ vs. $\sigma_{L, H V}^{\circ}$ & 0.77 & $1.3 \times 10^{-1}$ & -0.27 & $6.7 \times 10^{-1}$ & -0.21 & $7.3 \times 10^{-1}$ & 0.49 & $5.1 \times 10^{-1}$ \\
\hline$\sigma^{\circ} \mathrm{X}, \mathrm{HH}$ vs. $\sigma_{\mathrm{C}, \mathrm{HH}}^{\circ}$ & 0.78 & $1.2 \times 10^{-1}$ & 0.78 & $1.2 \times 10^{-1}$ & 0.29 & $6.4 \times 10^{-1}$ & -0.78 & $2.2 \times 10^{-1}$ \\
\hline$\sigma^{\circ}{ }_{\mathrm{C}, \mathrm{HH}}$ vs. $\sigma^{\circ}{ }_{\mathrm{L}, \mathrm{HH}}$ & - & - & 0.24 & $7.0 \times 10^{-1}$ & -0.85 & $6.8 \times 10^{-2}$ & -0.32 & $6.8 \times 10^{-1}$ \\
\hline$\sigma^{\circ} \mathrm{X}, \mathrm{HH}$ vs. $\sigma^{\circ}{ }_{\mathrm{L}, \mathrm{HH}}$ & - & - & - & - & $\overline{-0.83}$ & $8.0 \times 10^{-2}$ & -0.32 & $6.8 \times 10^{-1}$ \\
\hline$\sigma^{\circ}{ }_{C, H V}$ vs. $\sigma^{\circ}{ }_{L, H V}$ & -0.35 & $5.6 \times 10^{-1}$ & 0.58 & $3.1 \times 10^{-1}$ & $\overline{-0.80}$ & $\overline{1.1 \times 10^{-1}}$ & -0.29 & $7.0 \times 10^{-1}$ \\
\hline
\end{tabular}

Table 8. $r_{\mathrm{t}}$ vs. $h^{\prime}$ temporal correlations, $r_{\mathrm{t}}$, over the whole period for different crops; significant strong correlations ( $p$-value $<0.05,0.6<r<0.8$ ) are in light-gray highlighted with values in bold; quasi-significant correlations $(0.05<p$-value $<0.1)$ are outlined; very weak correlations $(r<0.19)$ are not reported.

\begin{tabular}{|c|c|c|c|c|c|c|c|c|c|c|}
\hline \multirow{3}{*}{$r_{\mathrm{s}}$} & \multicolumn{10}{|c|}{$r_{\mathrm{t}}$ between $r_{\mathrm{s}}$ and $h^{\prime}$} \\
\hline & \multicolumn{2}{|c|}{ Sugar Beet } & \multicolumn{2}{|c|}{ Barley } & \multicolumn{2}{|r|}{ Maize } & \multicolumn{2}{|r|}{ Rape } & \multicolumn{2}{|r|}{ Wheat } \\
\hline & $r$ & $p$-Value & $r$ & $p$-Value & $r$ & $p$-Value & $r$ & $p$-Value & $r$ & $p$-Value \\
\hline$\sigma^{\circ} \mathrm{X}, \mathrm{HH}$ vs. $\sigma^{\circ} \mathrm{X}, \mathrm{VV}$ & -0.35 & $6.5 \times 10^{-1}$ & 0.26 & $4.6 \times 10^{-1}$ & 0.56 & $2.4 \times 10^{-1}$ & 0.27 & $4.2 \times 10^{-1}$ & - & - \\
\hline$\sigma^{\circ} \mathrm{C}, \mathrm{HH}$ vs. $\sigma^{\circ} \mathrm{C}, \mathrm{VV}$ & -0.88 & $1.2 \times 10^{-1}$ & - & - & 0.29 & $5.8 \times 10^{-1}$ & 0.34 & $3.1 \times 10^{-1}$ & 0.47 & $2.1 \times 10^{-1}$ \\
\hline$\sigma^{\circ}{ }_{L, H H}$ vs. $\sigma^{\circ}{ }_{L, V V}$ & 0.31 & $6.9 \times 10^{-1}$ & 0.55 & $1.0 \times 10^{-1}$ & - & - & -0.35 & $2.9 \times 10^{-1}$ & - & - \\
\hline$\sigma^{\circ}{ }_{\mathrm{C}, \mathrm{HH}}$ vs. $\sigma^{\circ}{ }_{\mathrm{C}, \mathrm{HV}}$ & -0.70 & $3.0 \times 10^{-1}$ & 0.51 & $1.3 \times 10^{-1}$ & 0.48 & $3.4 \times 10^{-1}$ & 0.49 & $1.2 \times 10^{-1}$ & 0.52 & $1.5 \times 10^{-1}$ \\
\hline$\sigma^{\circ}{ }_{L, H H}$ vs. $\sigma^{\circ}{ }_{L, H V}$ & 0.55 & $4.5 \times 10^{-1}$ & -0.49 & $1.5 \times 10^{-1}$ & 0.28 & $6.0 \times 10^{-1}$ & -0.35 & $2.9 \times 10^{-1}$ & 0.53 & $1.4 \times 10^{-1}$ \\
\hline$\sigma^{\circ} \mathrm{X}, \mathrm{HH}$ vs. $\sigma^{\circ} \mathrm{C}, \mathrm{HH}$ & -0.70 & $3.0 \times 10^{-1}$ & - & - & 0.25 & $6.4 \times 10^{-1}$ & 0.44 & $1.7 \times 10^{-1}$ & 0.45 & $2.2 \times 10^{-1}$ \\
\hline$\sigma^{\circ} \mathrm{C}, \mathrm{HH}$ vs. $\sigma_{\mathrm{L}, \mathrm{HH}}^{\circ}$ & -0.66 & $3.4 \times 10^{-1}$ & 0.54 & $1.1 \times 10^{-1}$ & -0.24 & $6.5 \times 10^{-1}$ & - & - & 0.69 & $3.9 \times 10^{-2}$ \\
\hline$\sigma^{\circ} \mathrm{X}, \mathrm{HH}$ vs. $\sigma^{\circ}{ }_{\mathrm{L}, \mathrm{HH}}$ & 0.32 & $6.8 \times 10^{-1}$ & -0.68 & $3.1 \times 10^{-2}$ & - & - & 0.43 & $1.9 \times 10^{-1}$ & 0.45 & $2.2 \times 10^{-1}$ \\
\hline$\sigma^{\circ} \mathrm{C}, \mathrm{HV}$ vs. $\sigma_{\mathrm{L}, \mathrm{HV}}^{\circ}$ & -0.91 & $9.4 \times 10^{-2}$ & - & - & -0.31 & $5.5 \times 10^{-1}$ & -0.31 & $3.5 \times 10^{-1}$ & 0.28 & $4.5 \times 10^{-1}$ \\
\hline
\end{tabular}


Table 9. $r_{\mathrm{t}}$ vs. $m_{\mathrm{v}}$ temporal correlations, $r_{\mathrm{t}}$, over the whole period for different crops; significant correlations ( $p$-value $<0.05)$ are in light-gray highlighted; strong $(0.6<r<0.8)$ significant correlations are also bolded; very strong $(r>0.8)$ significant correlations are also highlighted in dark-gray; quasi-significant correlations $(0.05<p$-value $<0.1)$ are outlined; very weak correlations $(r<0.19)$ are not reported.

\begin{tabular}{|c|c|c|c|c|c|c|c|c|c|c|}
\hline \multirow{3}{*}{$r_{\mathrm{s}}$} & \multicolumn{10}{|c|}{$r_{\mathrm{t}}$ between $r_{\mathrm{s}}$ and $m_{\mathrm{v}}$} \\
\hline & \multicolumn{2}{|c|}{ Sugar Beet } & \multicolumn{2}{|c|}{ Barley } & \multicolumn{2}{|c|}{ Maize } & \multicolumn{2}{|c|}{ Rape } & \multicolumn{2}{|c|}{ Wheat } \\
\hline & $r$ & $p$-Value & $r$ & $p$-Value & $r$ & $p$-Value & $r$ & $p$-Value & $r$ & $p$-Value \\
\hline$\sigma^{\circ} \mathrm{x}, \mathrm{HH}$ vs. $\sigma^{\circ} \mathrm{x}, \mathrm{VV}$ & 0.24 & $7.6 \times 10^{-1}$ & - & - & - & - & - & - & -0.65 & $2.0 \times 10^{-3}$ \\
\hline$\sigma^{\circ} \mathrm{C}, \mathrm{HH}$ vs. $\sigma^{\circ} \mathrm{C}, \mathrm{VV}$ & - & - & - & - & 0.31 & $5.5 \times 10^{-1}$ & - & - & - & - \\
\hline$\sigma_{L, H H}^{\circ}$ vs. $\sigma_{L, V V}^{\circ}$ & -0.98 & $2.1 \times 10^{-2}$ & - & - & 0.61 & $2.0 \times 10^{-1}$ & -0.26 & $2.4 \times 10^{-1}$ & -0.38 & $\underline{9.7} \times 10^{-2}$ \\
\hline$\sigma^{\circ}{ }_{C, H H}$ vs. $\sigma^{\circ}{ }_{\mathrm{C}, \mathrm{HV}}$ & - & - & -0.48 & $3.2 \times 10^{-2}$ & -0.50 & $3.1 \times 10^{-1}$ & -0.23 & $2.9 \times 10^{-1}$ & $\overline{-}$ & $-\overline{-}$ \\
\hline$\sigma^{\circ}{ }_{L, H H}$ vs. $\sigma_{L, H V}^{\circ}$ & -0.97 & $2.9 \times 10^{-2}$ & -0.27 & $2.5 \times 10^{-1}$ & -0.67 & $1.5 \times 10^{-1}$ & -0.36 & $1.0 \times 10^{-1}$ & -0.33 & $1.5 \times 10^{-1}$ \\
\hline$\sigma^{\circ} \mathrm{X}, \mathrm{HH}$ vs. $\sigma^{\circ}{ }_{\mathrm{C}, \mathrm{HH}}$ & - & - & 0.26 & $2.7 \times 10^{-1}$ & -0.19 & $7.3 \times 10^{-1}$ & -0.20 & $3.6 \times 10^{-1}$ & - & - \\
\hline$\sigma^{\circ} \mathrm{C}, \mathrm{HH}$ vs. $\sigma^{\circ}, \mathrm{HH}$ & -0.33 & $6.7 \times 10^{-1}$ & - & - & -0.67 & $1.5 \times 10^{-1}$ & 0.20 & $3.8 \times 10^{-1}$ & - & - \\
\hline$\sigma^{\circ} \mathrm{X}, \mathrm{HH}$ vs. $\sigma_{\mathrm{L}, \mathrm{HH}}^{\circ}$ & -0.88 & $1.2 \times 10^{-1}$ & -0.23 & $3.3 \times 10^{-1}$ & -0.67 & $1.5 \times 10^{-1}$ & - & - & -0.49 & $2.8 \times 10^{-2}$ \\
\hline$\sigma^{\circ} \mathrm{C}, \mathrm{HV}$ vs. $\sigma^{\circ}{ }_{L, H V}$ & - & - & -0.28 & $2.3 \times 10^{-1}$ & -0.68 & $1.4 \times 10^{-1}$ & 0.24 & $2.8 \times 10^{-1}$ & -0.53 & $1.6 \times 10^{-2}$ \\
\hline
\end{tabular}

Table 10. $r_{\mathrm{t}}$ vs. $F_{\mathrm{v}}$ temporal correlations, $r_{\mathrm{t}}$, over the whole period for different crops; significant correlations ( $p$-value $<0.05)$ are in light-gray highlighted; strong $(0.6<r<0.8)$ significant correlations are also bolded; very strong $(r>0.8)$ significant correlations are also highlighted in dark-gray; quasi-significant correlations $(0.05<p$-value $<0.1)$ are outlined; very weak correlations $(r<0.19)$ are not reported.

\begin{tabular}{|c|c|c|c|c|c|c|c|c|c|c|}
\hline \multirow{3}{*}{$r_{\mathrm{s}}$} & \multicolumn{10}{|c|}{$r_{\mathrm{t}}$ between $r_{\mathrm{s}}$ and $F_{\mathrm{v}}$} \\
\hline & \multicolumn{2}{|c|}{ Sugar Beet } & \multicolumn{2}{|c|}{ Barley } & \multicolumn{2}{|c|}{ Maize } & \multicolumn{2}{|r|}{ Rape } & \multicolumn{2}{|r|}{ Wheat } \\
\hline & $r$ & $p$-Value & $r$ & $p$-Value & $r$ & $p$-Value & $r$ & $p$-Value & $r$ & $p$-Value \\
\hline$\sigma^{\circ} x, H H$ vs. $\sigma^{\circ} x, V v$ & 0.72 & $1.7 \times 10^{-1}$ & -0.41 & $7.3 \times 10^{-2}$ & -0.83 & $4.2 \times 10^{-2}$ & -0.21 & $3.5 \times 10^{-1}$ & - & - \\
\hline$\sigma^{\circ} \mathrm{C}, \mathrm{HH}$ vs. $\sigma^{\circ} \mathrm{C}, \mathrm{VV}$ & -0.44 & $4.6 \times 10^{-1}$ & $\overline{-0.41}$ & $\overline{7.0} \times 10^{-2}$ & -0.91 & $1.3 \times 10^{-2}$ & -0.33 & $1.3 \times 10^{-1}$ & 0.78 & $4.4 \times 10^{-5}$ \\
\hline$\sigma_{L, H H}^{\circ}$ vs. $\sigma_{L, V V}^{\circ}$ & -0.55 & $3.3 \times 10^{-1}$ & $\overline{0.28}$ & $2.4 \times 10^{-1}$ & -0.83 & $4.1 \times 10^{-2}$ & -0.46 & $2.9 \times 10^{-2}$ & - & - \\
\hline$\sigma^{\circ} \mathrm{C}, \mathrm{HH}$ vs. $\sigma^{\circ}{ }_{\mathrm{C}, \mathrm{HV}}$ & -0.65 & $2.3 \times 10^{-1}$ & - & - & -0.20 & $7.1 \times 10^{-1}$ & 0.23 & $3.0 \times 10^{-1}$ & 0.79 & $3.6 \times 10^{-5}$ \\
\hline$\sigma^{\circ}{ }_{L, H H}$ vs. $\sigma^{\circ}{ }_{L, H V}$ & -0.66 & $2.2 \times 10^{-1}$ & - & - & 0.42 & $4.1 \times 10^{-1}$ & - & - & - & - \\
\hline$\sigma^{\circ} \mathrm{X}, \mathrm{HH}$ vs. $\sigma^{\circ}{ }_{\mathrm{C}, \mathrm{HH}}$ & 0.30 & $6.2 \times 10^{-1}$ & -0.76 & $1.1 \times 10^{-4}$ & -0.57 & $2.4 \times 10^{-1}$ & -0.41 & $\underline{6.0 \times 10^{-2}}$ & 0.74 & $2.1 \times 10^{-4}$ \\
\hline$\sigma_{\mathrm{C}, \mathrm{HH}}^{\circ}$ vs. $\sigma_{\mathrm{L}, \mathrm{HH}}^{\circ}$ & -0.46 & $4.3 \times 10^{-1}$ & - & - & 0.29 & $5.8 \times 10^{-1}$ & $\overline{-0.36}$ & $9.8 \times 10^{-2}$ & 0.45 & $4.5 \times 10^{-2}$ \\
\hline$\sigma^{\circ} \mathrm{X}, \mathrm{HH}$ vs. $\sigma_{\mathrm{L}, \mathrm{HH}}^{\circ}$ & - & - & - & - & 0.31 & $5.5 \times 10^{-1}$ & $\overline{-0.35}$ & $1.1 \times 10^{-1}$ & - & - \\
\hline$\sigma^{\circ}{ }_{C, H V}$ vs. $\sigma^{\circ}{ }_{L, H V}$ & 0.32 & $5.9 \times 10^{-1}$ & - & - & - & - & -0.25 & $2.6 \times 10^{-1}$ & 0.25 & $2.9 \times 10^{-1}$ \\
\hline
\end{tabular}

Table 11. $r_{\mathrm{t}}$ vs. LAI temporal correlations, $r_{\mathrm{t}}$, over the whole period for different crops; significant correlations ( $p$-value $<0.05)$ are in light-gray highlighted; strong $(0.6<r<0.8)$ significant correlations are also bolded; quasi-significant correlations $(0.05<p$-value $<0.1)$ are outlined; very weak correlations $(r<0.19)$ are not reported.

\begin{tabular}{|c|c|c|c|c|c|c|c|c|c|c|}
\hline \multirow{3}{*}{$r_{\mathrm{s}}$} & \multicolumn{10}{|c|}{$r_{\mathrm{t}}$ between $r_{\mathrm{s}}$ and LAI } \\
\hline & \multicolumn{2}{|c|}{ Sugar Beet } & \multicolumn{2}{|c|}{ Barley } & \multicolumn{2}{|c|}{ Maize } & \multicolumn{2}{|r|}{ Rape } & \multicolumn{2}{|r|}{ Wheat } \\
\hline & $r$ & $p$-Value & $r$ & $p$-Value & $r$ & $p$-Value & $r$ & $p$-Value & $r$ & $p$-Value \\
\hline$\sigma^{\circ} \mathrm{X}, \mathrm{HH}$ vs. $\sigma^{\circ} \mathrm{X}, \mathrm{VV}$ & 0.55 & $3.3 \times 10^{-1}$ & 0.52 & $2.6 \times 10^{-2}$ & -0.49 & $4.0 \times 10^{-1}$ & - & - & 0.76 & $2.4 \times 10^{-4}$ \\
\hline$\sigma^{\circ} \mathrm{C}, \mathrm{HH}$ vs. $\sigma^{\circ} \mathrm{C}, \mathrm{VV}$ & -0.83 & $\underline{8.2} \times 10^{-2}$ & -0.26 & $2.9 \times 10^{-1}$ & -0.81 & $1.0 \times 10^{-1}$ & - & - & - & - \\
\hline$\sigma^{\circ}{ }_{L, H H}$ vs. $\sigma^{\circ}{ }_{L, V V}$ & $\overline{-}$ & - & -0.57 & $1.3 \times 10^{-2}$ & -0.83 & $\underline{8.2 \times 10^{-2}}$ & - & - & - & - \\
\hline$\sigma^{\circ}{ }_{C, H H}$ vs. $\sigma^{\circ}{ }_{C, H V}$ & -0.86 & $\underline{6.1} \times 10^{-2}$ & 0.42 & $\underline{8.3} \times 10^{-2}$ & $\overline{0.27}$ & $6.6 \times 10^{-1}$ & 0.32 & $1.7 \times 10^{-1}$ & 0.25 & $3.2 \times 10^{-1}$ \\
\hline$\sigma^{\circ}{ }_{L, H H}$ vs. $\sigma^{\circ}{ }_{L, H V}$ & - & - & $\overline{-0.48}$ & $\overline{4.2 \times 10^{-2}}$ & $\underline{0.84}$ & $\underline{7.3 \times 10^{-2}}$ & - & - & -0.30 & $2.3 \times 10^{-1}$ \\
\hline$\sigma^{\circ} \mathrm{X}, \mathrm{HH}$ vs. $\sigma^{\circ} \mathrm{C}, \mathrm{HH}$ & - & - & 0.39 & $1.1 \times 10^{-1}$ & - & - & - & - & 0.21 & $4.0 \times 10^{-1}$ \\
\hline$\sigma_{\mathrm{C}, \mathrm{HH}}^{\circ}$ vs. $\sigma_{\mathrm{L}, \mathrm{HH}}^{\circ}$ & -0.54 & $3.5 \times 10^{-1}$ & -0.69 & $1.4 \times 10^{-3}$ & 0.20 & $7.5 \times 10^{-1}$ & 0.19 & $4.1 \times 10^{-1}$ & - & - \\
\hline$\sigma^{\circ} \mathrm{X}, \mathrm{HH}$ vs. $\sigma^{\circ} \mathrm{L}, \mathrm{HH}$ & 0.40 & $5.1 \times 10^{-1}$ & -0.24 & $3.3 \times 10^{-1}$ & 0.25 & $6.9 \times 10^{-1}$ & - & - & - & - \\
\hline$\sigma^{\circ} \mathrm{C}, \mathrm{HV}$ vs. $\sigma^{\circ} \mathrm{L}, \mathrm{HV}$ & -0.74 & $1.5 \times 10^{-1}$ & -0.22 & $3.9 \times 10^{-1}$ & - & - & 0.46 & $3.9 \times 10^{-2}$ & $\underline{0.42}$ & $\underline{8.3} \times 10^{-2}$ \\
\hline
\end{tabular}

Over bare soils, a total of 36 correlations ( 9 band pairs, 2 soil variables, 2 crops) were evaluated. Only $13(\approx 30 \%) r_{\mathrm{t}}$ are moderate $(>\mid 0.6 \mathrm{l})$; most of them (6 cases) involve multi-frequency pairs. Conversely to the single regression approach, the inter-channel spatial/temporal correlation analysis pointed out three quasi-significant and very strong $r_{\mathrm{s}}$ vs. $h^{\prime}$ correlations (involving $\mathrm{X}_{\mathrm{HH}}-\mathrm{X}_{\mathrm{VV}}, \mathrm{C}_{\mathrm{HH}}-\mathrm{L}_{\mathrm{HH}}$, $\mathrm{X}_{\mathrm{HH}}-\mathrm{L}_{\mathrm{HH}}$ pairs). Best correlations will be further analyzed within the discussion section (Tables 12 and 13). 
Table 12. Best results achieved through the dynamic and correlation analyses; significant correlations are highlighted in light-grey, quasi-significant correlations are underlined; other correlations are not reported; for each correlation MAE is also reported.

\begin{tabular}{|c|c|c|c|c|c|c|c|c|c|c|c|c|c|c|}
\hline \multirow{4}{*}{ Channel } & \multirow{3}{*}{\multicolumn{2}{|c|}{$\begin{array}{c}\sigma^{\circ} \text { Dynamic Analysis }-\Delta \sigma^{\circ} \\
(\mathrm{dB})\end{array}$}} & \multicolumn{12}{|c|}{$\sigma^{\circ}$ vs. SVV Analysis } \\
\hline & & & \multicolumn{4}{|c|}{ Bare Soils } & \multicolumn{8}{|c|}{ Vegetated } \\
\hline & & & \multicolumn{2}{|c|}{$\sigma^{\circ}$ vs. $h^{\prime}$} & \multicolumn{2}{|c|}{$\sigma^{\circ}$ vs. $m_{\mathrm{v}}$} & \multicolumn{2}{|c|}{$\sigma^{\circ}$ vs. $h^{\prime}$} & \multicolumn{2}{|c|}{$\sigma^{\circ}$ vs. $m_{\mathrm{v}}$} & \multicolumn{2}{|c|}{$\sigma^{\circ}$ vs. $F_{\mathbf{v}}$} & \multicolumn{2}{|c|}{$\sigma^{\circ}$ vs. LAI } \\
\hline & $\begin{array}{c}\text { Varying } h^{\prime}, m_{\mathrm{v}} \\
F_{\mathrm{v}} \text { and } \mathrm{LAI} \\
\left(\Delta \sigma_{\text {avg }}^{\circ}\right)\end{array}$ & $\begin{array}{c}\text { Varying } \\
\text { LAI }\left(\Delta \sigma^{\circ}\right)\end{array}$ & $\begin{array}{c}r \\
(-)\end{array}$ & $\begin{array}{l}\text { MAE } \\
\text { (dB) }\end{array}$ & $\begin{array}{c}r \\
(-)\end{array}$ & $\begin{array}{l}\text { MAE } \\
\text { (dB) }\end{array}$ & $\begin{array}{c}r \\
(-)\end{array}$ & $\begin{array}{c}\text { MAE } \\
\text { (dB) }\end{array}$ & $\begin{array}{c}r \\
(-)\end{array}$ & $\begin{array}{l}\text { MAE } \\
\text { (dB) }\end{array}$ & $\begin{array}{c} \\
r \\
(-)\end{array}$ & $\begin{array}{c}\text { MAE } \\
\text { (dB) }\end{array}$ & $\begin{array}{c}r \\
(-)\end{array}$ & $\begin{array}{c}\text { MAE } \\
\text { (dB) }\end{array}$ \\
\hline $\mathrm{X}_{\mathrm{HH}}$ & 7.50 & 6.99 & - & - & $\underline{0.79}$ & 0.81 & - & - & 0.37 & 1.03 & 0.90 & 0.54 & 0.63 & 1.28 \\
\hline $\mathrm{X}_{\mathrm{VV}}$ & 7.20 & 6.16 & - & - & $\overline{0.82}$ & $\overline{0.66}$ & - & - & $\overline{0.46}$ & $\overline{1.05}$ & $\underline{0.85}$ & $\underline{0.74}$ & 0.62 & 1.48 \\
\hline $\mathrm{C}_{\mathrm{HH}}$ & 6.40 & 5.79 & - & - & 0.83 & 0.71 & - & - & $\underline{0.38}$ & $\underline{1.22}$ & 0.87 & 0.75 & 0.64 & 0.90 \\
\hline $\mathrm{C}_{\mathrm{HV}}$ & 10.00 & 10.39 & - & - & - & - & - & - & 0.46 & 1.41 & 0.90 & 0.62 & 0.91 & 0.54 \\
\hline$C_{V V}$ & 7.80 & 5.02 & - & - & - & - & - & - & - & - & $\underline{0.87}$ & $\underline{0.61}$ & - & - \\
\hline $\mathrm{L}_{\mathrm{HH}}$ & 11.40 & 11.72 & - & - & 0.99 & 0.24 & - & - & 0.51 & 2.44 & 0.87 & 0.76 & 0.98 & 0.29 \\
\hline $\mathrm{L}_{\mathrm{HV}}$ & 12.10 & 13.96 & - & - & 0.99 & 0.15 & - & - & 0.66 & 1.79 & 0.95 & 0.67 & 0.95 & 0.83 \\
\hline LVV & 11.30 & 10.95 & - & - & 0.99 & 0.22 & - & - & 0.55 & 1.61 & 0.90 & 0.83 & 0.89 & 0.88 \\
\hline
\end{tabular}

Table 13. Best results achieved through the inter-channel correlation analysis. Additionally, to the key legend of Table 12, improvements, with respect to the single regression approach, are highlighted in blue; bolded blue values refer to improvements achieved through the multi-frequency approach.

\begin{tabular}{|c|c|c|c|c|c|c|c|c|c|c|c|c|c|}
\hline & \multirow{3}{*}{ Channel Pairs } & \multicolumn{12}{|c|}{$r_{\mathrm{s}}$ vs. $S V V$ Analysis } \\
\hline & & \multicolumn{4}{|c|}{ Bare } & \multicolumn{8}{|c|}{ Vegetated } \\
\hline & & $\begin{array}{c}r_{\mathrm{s}} \mathrm{vs} . \\
h^{\prime}\end{array}$ & $\begin{array}{c}\text { MAE } \\
(-)\end{array}$ & $\begin{array}{c}r_{\mathrm{s}} \mathrm{vs} . \\
m_{\mathrm{v}}\end{array}$ & $\begin{array}{c}\text { MAE } \\
(-)\end{array}$ & $\begin{array}{c}r_{\mathrm{s}} \mathrm{vs} . \\
h^{\prime}\end{array}$ & $\begin{array}{c}\text { MAE } \\
(-)\end{array}$ & $\begin{array}{c}r_{\mathrm{s}} \text { vs. } \\
m_{\mathrm{v}}\end{array}$ & $\begin{array}{c}\text { MAE } \\
(-)\end{array}$ & $\begin{array}{c}r_{\mathrm{S}} \text { vs. } \\
F_{\mathrm{v}}\end{array}$ & $\begin{array}{c}\text { MAE } \\
(-)\end{array}$ & $\begin{array}{l}r_{\mathrm{s}} \mathrm{vs} . \\
\text { LAI }\end{array}$ & $\begin{array}{c}\text { MAE } \\
(-)\end{array}$ \\
\hline \multirow{5}{*}{$\begin{array}{c}r_{\mathrm{s}} \text { single } \\
\text { Freq. }\end{array}$} & $X_{\mathrm{HH}}$ vs. $X_{V V}$ & $\underline{0.88}$ & $\underline{0.02}$ & - & - & - & - & -0.65 & 0.05 & -0.83 & 0.02 & 0.76 & 0.04 \\
\hline & $\mathrm{C}_{\mathrm{HH}}$ vs. $\mathrm{C}_{\mathrm{VV}}$ & $\overline{-}$ & - & - & - & - & - & - & - & -0.91 & 0.02 & -0.83 & 0.03 \\
\hline & $\mathrm{L}_{\mathrm{HH}}$ vs. $\mathrm{L}_{\mathrm{VV}}$ & - & - & - & - & - & - & -0.98 & 0.01 & -0.83 & 0.03 & $\overline{-0.57}$ & $\overline{0.13}$ \\
\hline & $\mathrm{C}_{\mathrm{HH}}$ vs. $\mathrm{C}_{\mathrm{HV}}$ & - & - & - & - & - & - & -0.48 & 0.05 & 0.79 & 0.07 & -0.86 & $\underline{0.07}$ \\
\hline & $\mathrm{L}_{\mathrm{HH}}$ vs. $\mathrm{L}_{\mathrm{HV}}$ & - & - & - & - & - & - & -0.97 & 0.04 & - & - & $\overline{-0.48}$ & $\overline{0.18}$ \\
\hline \multirow{4}{*}{$r_{\mathrm{s}}$ dual Freq. } & $\mathrm{X}_{\mathrm{HH}}$ vs. $\mathrm{C}_{\mathrm{HH}}$ & - & - & - & - & - & - & - & - & -0.76 & 0.08 & - & - \\
\hline & $\mathrm{C}_{\mathrm{HH}}$ vs. $\mathrm{L}_{\mathrm{HH}}$ & -0.85 & $\underline{0.05}$ & - & - & 0.69 & 0.09 & - & - & 0.45 & 0.13 & -0.69 & 0.18 \\
\hline & $\mathrm{X}_{\mathrm{HH}}$ vs. $\mathrm{L}_{\mathrm{HH}}$ & $\overline{-0.83}$ & $\overline{0.08}$ & - & - & -0.68 & 0.07 & -0.49 & 0.16 & - & - & - & - \\
\hline & $\mathrm{C}_{\mathrm{HV}}$ vs. $\mathrm{L}_{\mathrm{HV}}$ & - & - & - & - & -0.91 & $\underline{0.07}$ & -0.53 & 0.09 & - & - & 0.46 & 0.10 \\
\hline
\end{tabular}

Over vegetated areas, among 180 correlations (9 band couples, 4 soil-vegetation variables, 5 crops), only $34(\approx 18 \%) r_{\mathrm{t}}$ were higher than $|0.6| ; 14$ are strong and very strong significant correlations and 5 of these involve multi-frequency combinations (Tables 8-11).

Over vegetated areas, $r_{\mathrm{s}}$ vs. $h^{\prime}$ produces the lowest number of significant correlations as, in this case, $\sigma^{\circ}$ is mainly ruled by canopy dielectric (plant water content) and geometric properties $\left(L A I, F_{\mathrm{V}}\right.$ and vegetation structure).

However, conversely to the single regression analysis, the dual-frequencies inter-channel spatial/temporal approach pointed out some strong significant correlations. Despite $r_{\mathrm{t}}$ were computed over vegetated plots, some negative strong and very strong significant $r_{\mathrm{t}}$ were observed between $r_{\mathrm{S}}$ and $m_{\mathrm{V}}$ for pairs of $\sigma^{\circ}$ at $\mathrm{L}$ and $\mathrm{X}$ frequencies. These results partially confirm the suitability of dual frequency approach to quantify $m_{\mathrm{v}}$ and biomass ( $F_{\mathrm{v}}$ particularly), as already reported by other authors [16,58]; further discussion about the improvements achievable through the multi-channel approach and the multi-frequency correlation will be provided in the next section.

\section{Discussion on Best Results Achieved}

This section summarizes best results achieved from the dynamic and single regression analyses (Table 12). Due to the reciprocity property of cross-polarizations, only outcomes achieved by using $\sigma^{\circ} \mathrm{HV}$ and $\sigma^{\circ}$ pp channels are further discussed. In addition, this part will be focused on the quasi- and significant correlations only. 
The dynamic analysis highlighted that $\Delta \sigma^{\circ}$ at $\mathrm{C}_{\mathrm{HV}}$ and $\mathrm{L}$ frequency generally showed the highest $\Delta \sigma^{\circ}(\approx 10-12 \mathrm{~dB})$; however, individual contributions of $h^{\prime}, m_{\mathrm{v}}, F_{\mathrm{v}}$ and LAI were not definitely distinguishable.

By observing $\Delta \sigma^{\circ}$ due to vegetation variations (i.e., changes in $L A I$ and $\left.F_{\mathrm{v}}\right) \Delta \sigma^{\circ}$ pq are higher at $\mathrm{L}(\sim 14 \mathrm{~dB})$ rather than at $C$ frequency $(\sim 10 \mathrm{~dB})$; this is probably due to the structure of sugar beet characterized by very large leaves. Moreover, as confirmed by other studies, $\sigma^{\circ} \mathrm{HV}$ and $\sigma^{\circ} \mathrm{VH}$ (not shown here) behave quite similarly according to the reciprocity principle, which for most natural media assumes a symmetric scattering matrix [59].

The correlation analysis highlights that over bare soils, $\sigma^{\circ}$ vs. $m_{\mathrm{v}}$ are significant and characterized by high $r$ at all channels with exceptions of $\mathrm{C}_{\mathrm{HV}}$ and $\mathrm{C}_{\mathrm{VV}}$. The highest $r$ and the lowest MAE were found at $\mathrm{L}$ frequency. Whereas no significant $\sigma^{\circ}$ vs. $h^{\prime}$ correlations were achieved.

Over vegetated areas, since $h^{\prime}$ was measured below canopy, no significant $r$ values have been found as $\sigma^{\circ}$ over dense vegetation is mainly ruled by: (i) surface water contents ( $m_{\mathrm{V}}$ and canopy water content) and (ii) surface roughness (correlated with biomass variables, including $L A I$ and $F_{\mathrm{V}}$, and vegetation structure). Quasi-significant and significant moderate to strong correlations (i.e., $0.4<r<0.8$ ) characterized $\sigma^{\circ}$ vs. $m_{\mathrm{v}}$ at all channels with the exception of $\mathrm{C}_{\mathrm{VV}}$. The highest $r$ values were found at $\mathrm{L}$ frequency probably due to the higher ability of longer waves to penetrate the canopy layer.

Very strong correlations (i.e., $r>0.8$ ) were found for $\sigma^{\circ}$ vs. $F_{\mathrm{v}}$ at all frequencies and polarizations; highest $r$ characterized $\sigma^{\circ}$ vs. $F_{\mathrm{v}}$ at $\mathrm{X}_{\mathrm{HH}}, \mathrm{C}_{\mathrm{HV}}$ and $\mathrm{L}_{\mathrm{HV}}$ comparisons. Strong to very strong $r$ characterized $\sigma^{\circ}$ vs. LAI comparisons with the highest values at $\mathrm{C}_{\mathrm{HV}}$ and $\mathrm{L}$ frequencies.

All these results highlight that, on the average, $\sigma^{\circ}$ at $\mathrm{L}$ bands are more suitable than others to infer SVV over both bare and vegetated areas.

It has been observed that, usually, correlations showing the highest $r$ were also characterized by the lower MAE (although this is not a general rule). Over bare soils and for all channels, lower MAE were found for $\sigma^{\circ}$ vs. $m_{\mathrm{v}}$ (MAE was $\approx 0.6 \mathrm{~dB}$ on average) with respect to the vegetated soils $(\approx 1.3 \mathrm{~dB})$. Lower MAE characterized both $\sigma^{\circ}$ vs. $F_{\mathrm{v}}$ and $\sigma^{\circ}$ vs. $L A I$ (on average $\approx 0.7 \mathrm{~dB}$ and $\approx 1 \mathrm{~dB}$, respectively) if compared to $\sigma^{\circ}$ vs. $m_{\mathrm{v}}$. Finally, lowest MAE were found at L frequency for $\sigma^{\circ} \mathrm{vs} . m_{\mathrm{v}}$ (bare soils) and for $\sigma^{\circ}$ vs. $F_{\mathrm{v}}$ and $\sigma^{\circ}$ vs. $L A I$ (vegetated plots).

Over bare soils, the inter-channel correlation analysis (Table 13) revealed three quasi-significant and very strong $r_{\mathrm{s}}$ vs. $h^{\prime}$ correlations; thus, it was observed a remarkable improvement with respect to the single frequency approach. However, no significant $r_{\mathrm{s}}$ vs. $m_{\mathrm{v}}$ correlations were found, meaning that all channel pairs were useless to assess $m_{\mathrm{v}}$ by means of this approach.

Improvements with regards to the single regression approach (Table 13, highlighted in red) were observed in several cases; the dual-frequency approach allowed pointing out higher correlations (Table 13, bolded red values) if compared to the single-frequency approach. Remarkably, $r_{\mathrm{s}}$ seems to be negatively correlated with SVV with some exceptions (see Tables 7-11). These exceptions are probably linked to the vegetation structure (as most of them were found for $F_{\mathrm{v}}$ and $L A I$ for the wheat plot); however, further analyses are required to corroborate this hypothesis. Further investigations could be carried out by employing multi-mission satellite data (e.g., using nowadays imagery acquired by Cosmo-SkyMed, TerraSAR-X, Palsar and Sentinel 1).

Over vegetated plots in particular, the more suitable band pairs to assess $m_{\mathrm{V}}$ were $\mathrm{L}_{\mathrm{HH}}-\mathrm{L}_{\mathrm{VV}}$ and $\mathrm{L}_{\mathrm{HH}}-\mathrm{L}_{\mathrm{HV}}\left(r_{\mathrm{t}}>\mid 0.97 \mathrm{I}\right)$; however, the inter-channel approach opens the possibility to assess $m_{\mathrm{v}}$ for all pairs except $\mathrm{C}_{\mathrm{HH}}-\mathrm{C}_{\mathrm{VV}}, \mathrm{X}_{\mathrm{HH}}-\mathrm{C}_{\mathrm{HH}}$ and $\mathrm{C}_{\mathrm{HH}}-\mathrm{L}_{\mathrm{HH}}$.

As for the $m_{\mathrm{V}}$, several channel pairs are suitable to assess $F_{\mathrm{V}}$ (strong to very strong significant correlations) with the exception of the $\mathrm{C}_{\mathrm{HH}}-\mathrm{L}_{\mathrm{HH}}$ pair. Channel pairs more suitable to assess $L A I$ are: $\mathrm{X}_{\mathrm{HH}}-\mathrm{X}_{\mathrm{VV}}, \mathrm{C}_{\mathrm{HH}}-\mathrm{L}_{\mathrm{HH}}, \mathrm{C}_{\mathrm{HV}}-\mathrm{L}_{\mathrm{HV}}$. 


\section{Conclusions}

The paper reports a detailed analysis on the influence of main SVV on $\sigma^{\circ}$. Statistical analyses have been carried out to define suitable frequencies/polarimetry configuration to characterize the main SVV over bare and vegetated plots. Dataset includes X, C and L SAR bands with HH, VV, VH and HV polarizations and in situ measurements.

The dynamic and correlation analyses investigate the behavior of single bands with changing SVV. The inter-channel correlation analysis explores the behavior of band pairs with SVV changing over time.

The dynamic analysis revealed that cross-polarized channels exhibit higher sensitiveness to SVV, in particular to $L A I$ and $F_{\mathrm{v}}$.

The single correlation analysis revealed that: (i) over bare soil, $\sigma^{\circ}$ vs. $m_{\mathrm{v}}$ exhibits strong and very strong correlation at all channels; best $r$ characterizes $\sigma^{\circ}$ vs. $m_{\mathrm{v}}$ at $\mathrm{L}$ channels $(r \sim 1)$; (ii) over vegetated areas, highest $r$ characterizes $\sigma^{\circ}$ vs. $F_{\mathrm{v}}$ and $\sigma^{\circ}$ vs. $L A I$ with best suitable channels at L frequency.

The inter-channel correlation (using a single frequency) displayed significant $r_{\mathrm{s}} \mathrm{vs} . h^{\prime}$ correlations over both bare and vegetated plots (unachievable by means of the single regression approach). The inter-channel spatial/temporal regression analysis is more suitable than the single channel approach in several cases. Thus, the inter-channel correlation analyses promise to retrieve other SVV with good accuracies even over vegetated plots. In some cases, best correlations are found by adopting the dual frequency approach compared to the use of a single frequency.

Despite all the analyses confirming that $L$ bands are more suitable than others to infer SVV over both bare and vegetated plots, few satellite sensors provide SAR data at L frequency (PALSAR 1 and 2); as a consequence, in the past, most of the models (see Table 1) have been implemented on $C$ and $X$ bands only (widely available). In addition, the NASA JPL's Soil Moisture Active Passive (SMAP), a mission launched at the end of 2015, partially failed after collecting just two months of data because of the malfunctioning of the SAR ( $\mathrm{L}_{\mathrm{VV}}, \mathrm{L}_{\mathrm{HH}}$, and $\left.\mathrm{L}_{\mathrm{HV}}\right)$.

Based on the results achieved by means of the inter-channel analysis, it could be interesting to perform further experiments exploiting data collected also by the near future SAR sensors; including: (i) SAOCOM-CONAE 1A/1B (Argentina) an L band two-satellite flying in constellation with COSMO-SkyMed; (ii) Tandem-L (DLR-Germany) a two formation-flying radar satellites operating in L band (planned to be launched at the end of 2022), and (iii) NISAR (NASA JPL-United States, 2020) that will include both $\mathrm{L}$ and $\mathrm{S}$ band polarimetry SAR sensors. These new experiments could be carried out coupling SAR to optical retrieved vegetation biomass (e.g., by means of Sentinel 2 or Landsat 8) and soil water content (e.g., through the use of passive microwave) maps. Thus, widening the study area these new researches could point out expected limitations in the relationship's inversion.

Acknowledgments: The authors thank the German Aerospace Center (Deutsches Zentrum für Luft- und Raumfahrt-DLR) for acquiring the radar images within the ESA-funded project AgriSAR 2006. A special thank both to the Leibnitz-Zentrum für Agrarlandschaftsforschung (ZALF) and University of Kiel (Christian-Albrechts-Universität, Department of Geography) for having carried out a consistent in situ dataset and the Instituto Nacional de Técnica Aeroespacial of Torrejón de Ardoz of Madrid (INTA institute) for radiometric calibrating and atmospherically correcting the optical images.

Author Contributions: F.C. designed and performed the sensitivity analysis; F.C. and A.M. analyzed the results; all the authors wrote and approved the paper.

Conflicts of Interest: The authors declare no conflicts of interest.

\section{Abbreviations}

The following abbreviations are used in this manuscript:

$\mathrm{i}, \mathrm{j} \quad$ subscripts indicating generic bands

$p p, p q \quad$ subscripts indicating like and cross polarizations

ASAR Advanced Synthetic Aperture Radar

AirSAR Airborne Synthetic Aperture Radar 


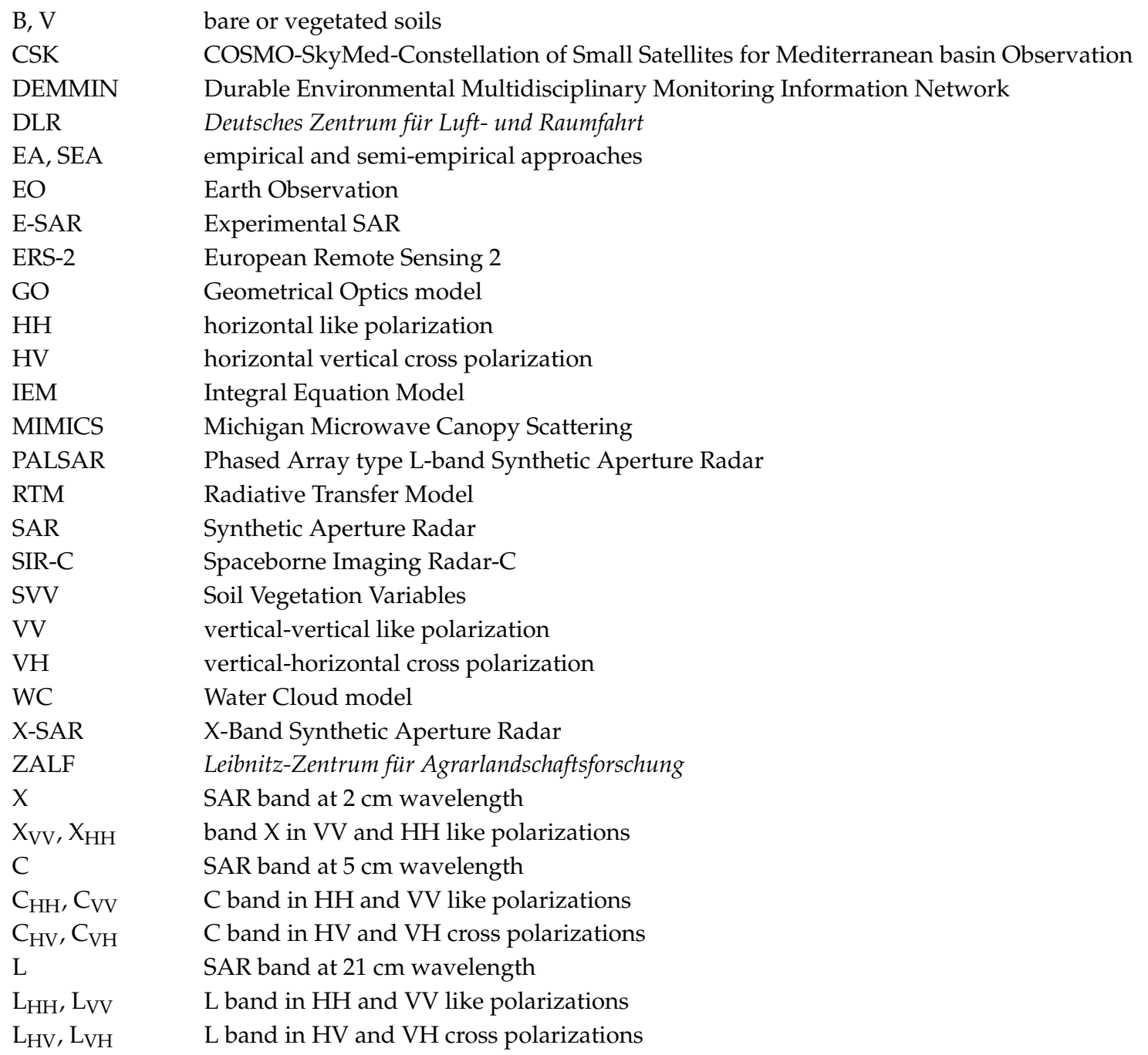

\section{Symbols}

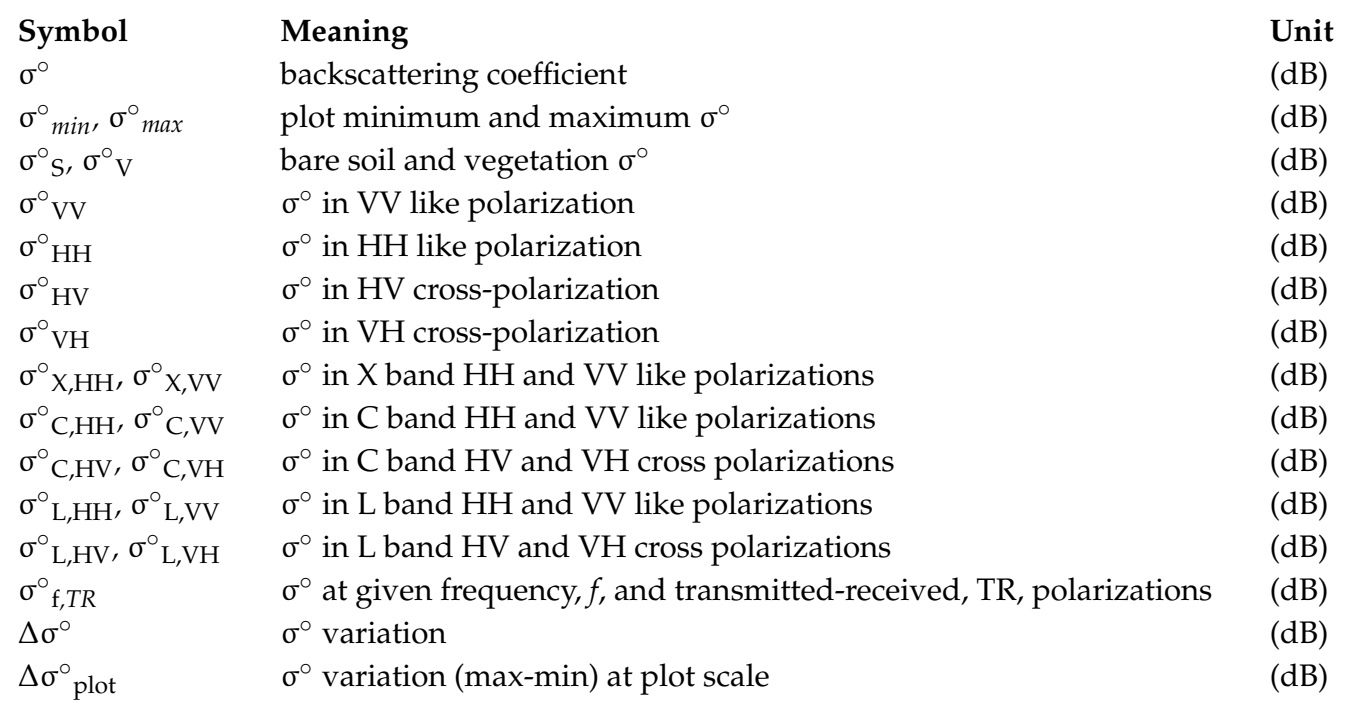




$\begin{array}{lll}\Delta \sigma^{\circ}{ } \text { avg } & \text { average of the } \Delta \sigma^{\circ} \text { plot values computed for all plots } & (\mathrm{dB}) \\ \Delta \sigma^{\circ}{ }_{\text {stdev }} & \text { standard deviation of the } \Delta \sigma^{\circ} \text { plot values computed for all plots } & (\mathrm{dB}) \\ I_{\mathrm{M}} & \text { Moran Index } & (-) \\ I_{\mathrm{S}} & \text { Speckle Index } & (-) \\ R_{\mathrm{S}} & \text { spatial resolution } & (\mathrm{m}) \\ h^{\prime} & \text { roughness height } & (\mathrm{m}) \\ m_{\mathrm{V}} & \text { volumetric soil water content } & \left(\mathrm{m}^{3} \mathrm{~m}^{-3}\right) \\ L A I & \text { Leaf Area Index } & \left(\mathrm{m}^{2} \mathrm{~m}^{-2}\right) \\ F_{\mathrm{V}} & \text { Fractional cover } & (-) \\ m, q & \text { slope and intercept of a linear regression line } & \text { variable dependent } \\ r, r^{2} & \text { Pearson correlation and determination coefficients } & (-) \\ r m s e, m s e & \text { root mean square error or mean square error } & \text { variable dependent } \\ r_{\mathrm{sp}} & \text { Spatial correlation image between two channels } & (-) \\ r_{\mathrm{S}} & \text { For each plot is a representative spatial correlation value obtained by } & (-) \\ & \text { averaging pixels of } r_{\text {sp }} \text { co-localized to in situ measures } & (-)\end{array}$

\section{Appendix A}

This appendix reports notes of Table 1.

\begin{tabular}{|c|c|}
\hline Note & Description \\
\hline * & performance not quantified; \\
\hline$i$ & $\sigma^{\circ}$ vs. in situ $m_{\mathrm{v}}$ for incidence angles of $25^{\circ}(\mathrm{a})$ and $50^{\circ}(\mathrm{b})$; \\
\hline$i i$ & $\begin{array}{l}\sigma^{\circ} \text { vs. in situ } m_{\mathrm{v}} \text { in the } \mathrm{HH} \text { polarization: }(\mathrm{a}, \mathrm{b}) \text { for } m_{\mathrm{v}} \text { measured with a Thetaprobe instrument at } \\
\text { a depth of } 5 \mathrm{~cm} \text {, at } 36^{\circ} \text { and } 26^{\circ} \text { incidence; }(\mathrm{c}, \mathrm{d}) \text { for } m_{\mathrm{v}} \text { measured by gravimetric sampling at } \\
\text { a depth of } 2 \mathrm{~cm} \text {, at } 36^{\circ} \text { and } 26^{\circ} \text { incidence; }\end{array}$ \\
\hline iii & $\begin{array}{l}\text { (a) linear regression model at low incidence angle; (b) linear regression model using low and high } \\
\text { incidence angle; }\end{array}$ \\
\hline$i v$ & Environment Canada (EC) network measurements (a) and sampled fields measurements (b); \\
\hline$v$ & Retrieved using $\mathrm{HH}$ and $\mathrm{HV}$ polarizations; \\
\hline$v i$ & $\begin{array}{l}\text { (a) bare soil: (b) vegetated soil. } m_{\mathrm{V}} \text { retrieved using } \mathrm{L} \text { bands only; a sensitivity analysis using the } \\
\text { full multi-frequency dataset is also presented; }\end{array}$ \\
\hline vii & (a) Bayesian and (b) Neural network approaches; \\
\hline viii & $r$ between measured and extracted $m_{\mathrm{v}}$ for (a) $\mathrm{C}$ band and (b) L band; \\
\hline$i x$ & $\begin{array}{l}\text { In situ } m_{\mathrm{V}} \text { vs. and } C \text { band retrieved } m_{\mathrm{V}} \text {, obtained by the ratio method (a) and water cloud } \\
\text { model (b); }\end{array}$ \\
\hline$x$ & bare soil (a) and vegetated soil (b); \\
\hline$x i$ & $\begin{array}{l}\text { Best performances retrieved with multiple linear regression at } C \text { and } L \text { bands: (a) } C_{H H} \text { and } \\
\text { (b) } L_{H V} \text {. }\end{array}$ \\
\hline
\end{tabular}

\section{References}

1. Dubois, P.C.; van Zyl, J.; Engman, T. Measuring soil moisture with imaging radars. IEEE Trans. Geosci. Remote Sens. 1995, 33, 915-926. [CrossRef]

2. Oh, Y.; Sarabandi, K.; Ulaby, F.T. An Empirical Model and an Inversion Technique for Radar Scattering from Bare Soil Surfaces. IEEE Trans. Geosci. Remote Sens. 1992, 30, 370-381. [CrossRef]

3. Oh, Y.; Sarabandi, K.; Ulaby, F.T. Semi-empirical model of the ensemble-averaged differential mueller matrix for microwave backscattering from bare soil surfaces. IEEE Trans. Geosci. Remote Sens. 2002, 40, 1348-1355. [CrossRef]

4. Fung, A.K. Microwave Scattering and Emission Models and Their Applications; Artech House: Boston, MA, USA, 1994; 592p.

5. Fung, A.K.; Li, Z.; Chen, K.S. Backscattering from a randomly rough dielectric surface. IEEE Trans. Geosci. Remote Sens. 1992, 30, 356-369. [CrossRef] 
6. Evans, D.L.; Fan, T.G.; van Zyl, J.J. Estimates of surface roughness derived from synthetic aperture radar (SAR) data. IEEE Trans. Geosci. Remote Sens. 1992, 30, 382-389. [CrossRef]

7. Moran, M.S.; Hymer, D.C.; Yann Kerr, J.Q. Comparison of ERS-2 SAR and Landsat TM imagery for monitoring agricultural crop and soil conditions. Remote Sens. Environ. 2002, 79, 243-252. [CrossRef]

8. Capodici, F.; La Loggia, G.; D’Urso, G.; Maltese, A.; Ciraolo, G. Surface soil humidity retrieval by means of a semi-empirical coupled SAR model. In Image and Signal Processing for Remote Sensing X; SPIE: Bellingham, WA, USA, 2010; Volume 7824, pp. 782427-1-782427-8.

9. Jackson, T.J.; McKee, L. Soil Roughness Measurements in the Walnut Creek Watershed during SMEX02. Available online: http://nsidc.org/data/docs/daac/nsidc0204_smex_ancillary.gd.html (accessed on 5 April 2017).

10. Karam, M.A.; Fung, A.K. Electromagnetic scattering from a layer of finite length, randomly oriented, dielectric circular cylinders over a rough interface with application to vegetation. Int. J. Remote Sens. 1988, 9, 1109-1134. [CrossRef]

11. Lang, R.H.; Sidhu, J.S. Electromagnetic backscattering from a layer of vegetation: A discrete approach. IEEE Trans. Geosci. Remote Sens. 1983, 21, 62-71. [CrossRef]

12. Tsang, L.; Kong, J. Application of strong fluctuation random medium theory to scattering from vegetation-like half space. IEEE Trans. Geosci. Remote Sens. 1981, 19, 62-69. [CrossRef]

13. Dobson, M.C.; Pierce, L.; Sarabandi, K.; Ulaby, F.T.; Sharik, T. Preliminary- analysis of ERS-1 SAR for forest ecosystem studies. IEEE Trans. Geosci. Remote Sens. 1992, 30, 203-211. [CrossRef]

14. Imhoff, M.L. Radar backscatter and biomass saturation: Ramifications for global biomass inventory. IEEE Trans. Geosci. Remote Sens. 1995, 33, 511-518. [CrossRef]

15. Pierce, L.E.; Dobson, M.C.; Wilcox, E.; Ulaby, F.T. Artificial neural network inversion of tree canopy parameters in the presence of diversity. Proceedings of IGARSS 1993: Better Understanding of Earth Environment, Tokyo, Japan, 12-21 August 1993; IEEE Press: Piscataway, NJ, USA, 1993; Volume 93, pp. 394-397.

16. Ranson, K.J.; Sun, G. Mapping biomass of a northern forest using multifrequency SAR data. IEEE Trans. Geosci. Remote Sens. 1994, 32, 388-396. [CrossRef]

17. Attema, E.P.W.; Ulaby, F.T. Vegetation modeled as a water cloud. Radio Sci. 1978, 13, 357-364. [CrossRef]

18. Ulaby, F.T.; Sarabandi, K.; McDonald, K.; Whitt, M.; Dobson, M.C. Michigan microwave canopy scattering model. Int. J. Remote Sens. 1990, 11, 1223-1253. [CrossRef]

19. Aubert, M.; Baghdadi, N.; Zribi, M.; Douaoui, A.; Loumagne, C.; Baup, F.; El Hajj, M.; Garrigues, S. Analysis of TerraSAR-X data sensitivity to bare soil moisture, roughness, composition and soil crust. Remote Sens. Environ. 2011, 115, 1801-1810. [CrossRef]

20. Gorrab, A.; Zribi, M.; Baghdadi, N.; Mougenot, B.; Chabaane, Z.L. Potential of X-Band TerraSAR-X and COSMO-SkyMed SAR Data for the Assessment of Physical Soil Parameters. Remote Sens. 2015, 7, 747-766. [CrossRef]

21. Oh, Y.; Kwon, S.G.; Hwang, J.H. Soil moisture detection algorithm at X-band. In Proceedings of the 3rd International Asia-Pacific Conference on Synthetic Aperture Radar (APSAR), Seoul, Korea, 26-30 September 2011; IEEE Press: Piscataway, NJ, USA, 2011; pp. 1-4.

22. Verhoest, N.E.C.; De Baets, B.; Mattia, F.; Satalino, G.; Lucau, C.; Defourny, P. A possibilistic approach to soil moisture retrieval from ERS synthetic aperture radar backscattering under soil roughness uncertainty. Water Resour. Res. 2007, 43, W07435. [CrossRef]

23. Moran, M.S.; Hymer, C.D.; Qi, J.; Sano, E. Soil moisture evaluation using multi-temporal synthetic aperture radar (SAR) in semiarid rangeland. Agric. For. Meteorol. 2000, 105, 69-80. [CrossRef]

24. Alvarez-Mozos, J.; Casalì, J.; González-Audícana, M.; Verhoest, N.E.C. Assessment of the Operational Applicability of RADARSAT-1 Data for Surface Soil Moisture Estimation. IEEE Trans. Geosci. Remote Sens. 2006, 44, 913-924. [CrossRef]

25. Lakhankar, T.; Ghedira, H.; Khanbilvardi, R. Soil moisture retrieval from RADARSAT data: A Neuro-Fuzzy approach. In Proceedings of the IEEE International Symposium on Geoscience and Remote Sensing, Denver, CO, USA, 31 July-4 August 2006; IEEE Press: Piscataway, NJ, USA; pp. 2328-2331.

26. Said, S.; Kothyari, U.C.; Arora, M.K. ANN-based soil moisture retrieval over bare and vegetated areas using ERS-2 SAR data. J. Hydrol. Eng. 2008, 13, 461-475. [CrossRef] 
27. Pathe, C.; Wagner, W.; Sabel, D.; Doubkova, M.; Basara, J.B. Using ENVISAT ASAR global mode data for surface soil moisture retrieval over Oklahoma, USA. IEEE Trans. Geosci. Remote Sens. 2009, 47, 468-480. [CrossRef]

28. Srivastava, H.S.; Patel, P.; Manchanda, M.L.; Adiga, S. Use of multi-incidence angle RADARSAT-1 SAR data to incorporate the effect of surface roughness in soil moisture estimation. IEEE Trans. Geosci. Remote Sens. 2003, 41, 1638-1640. [CrossRef]

29. Srivastava, H.S.; Patel, P.; Navalgund, R.R. Incorporating soil texture in soil moisture estimation from extended low-1 beam mode RADARSAT-1 SAR data. Int. J. Remote Sens. 2006, 27, 2587-2598. [CrossRef]

30. Mattia, F.; Satalino, G.; Dente, L.; Pasquariello, G. Using a priori information to improve soil moisture retrieval from ENVISAT ASAR AP data in semiarid regions. IEEE Trans. Geosci. Remote Sens. 2006, 44, 900-912. [CrossRef]

31. Song, X.; Ma, J.; Li, X.; Leng, P.; Zhou, F.; Li, S. First Results of Estimating Surface Soil Moisture in the Vegetated Areas Using ASAR and Hyperion Data: The Chinese Heihe River Basin Case Study. Remote Sens. 2014, 6, 12055-12069. [CrossRef]

32. Baghdadi, N.; Holah, N.; Zribi, M. Calibration of the integral equation model for SAR data in C-band and $\mathrm{HH}$ and VV polarizations. Int. J. Remote Sens. 2006, 27, 805-816. [CrossRef]

33. Gherboudj, I.; Magagi, R.; Berg, A.A.; Toth, B. Soil moisture retrieval over agricultural fields from multi-polarized and multi-angular RADARSAT-2 SAR data. Remote Sens. Environ. 2011, 115, 33-43. [CrossRef]

34. Jacome, A.; Bernier, M.; Chokmani, K.; Gauthier, Y.; Poulin, J.; De Sève, D. Monitoring Volumetric Surface Soil Moisture Content at the La Grande Basin Boreal Wetland by Radar Multi Polarization Data. Remote Sens. 2013, 5, 4919-4941. [CrossRef]

35. Paloscia, S.; Pettinato, S.; Santi, E.; Notarnicola, C.; Pasolli, L.; Reppucci, A. Soil moisture mapping using Sentinel-1 images: Algorithm and preliminary validation. Remote Sens. Environ. 2013, 134, $234-248$. [CrossRef]

36. Koyama, C.N.; Schneider, K. IEEE International. Soil moisture retrieval under vegetation using dual polarized PALSAR data. In Geoscience and Remote Sensing Symposium (IGARSS); IEEE Press: Piscataway, NJ, USA, 2011.

37. Rodionova, N.V. A Combined Use of Decomposition and Empirical Model for Soil Moisture Estimation in Vegetated Areas from polarimetric SAR Data. In Proceedings of the 7th European Conference on Synthetic Aperture Radar (EUSAR), Friedrichshafen, Germany, 2-5 June 2008; IEEE Press: Piscataway, NJ, USA, 2008; pp. 1-4.

38. Prakash, R.; Singh, D.; Pathak, N.P. A Fusion Approach to Retrieve Soil Moisture with SAR and Optical Data. IEEE J. Sel. Top. Appl. Earth Obs. Remote Sens. 2012, 5, 196-206. [CrossRef]

39. Koyama, C.N.; Sato, M. Soil Moisture and Biomass Retrieval using ALOS/PALSAR Data. Proceedings of Asia-Pacific Conference on Synthetic Aperture Radar (APSAR), Tsukuba, Japan, 23-27 September 2013; IEEE Press: Piscataway, NJ, USA, 2013; pp. 49-52.

40. Capodici, F.; Maltese, A.; Ciraolo, G.; La Loggia, G.; D’Urso, G. Coupling two radar backscattering models to assess soil roughness and surface water content at farm scale. Hydrol. Sci. J. 2013, 58, 1677-1689. [CrossRef]

41. Jagdhuber, T.; Hajnsek, I.; Papathanassiou, K.P. Refined Soil Moisture Estimation by means of L-Band Polarimetry. Proceedings of IEEE International Symposium on Geoscience and Remote Sensing (IGARSS), Beijing, China, 21-26 July 2013; IEEE Press: Piscataway, NJ, USA, 2013; pp. 2325-2328.

42. Notarnicola, C.; Angiulli, M.; Posa, F. Soil moisture retrieval from remotely sensed data: Neural network approach versus Bayesian method. IEEE Trans. Geosci. Remote Sens. 2008, 46, 547-557. [CrossRef]

43. Notarnicola, C.; Angiulli, M.; Posa, F. Use of radar and optical remotely sensed data for soil moisture retrieval over vegetated areas. IEEE Trans. Geosci. Remote Sens. 2006, 44, 925-935. [CrossRef]

44. Joseph, A.T.; van der Velde, R.; O'Neill, P.E.; Lang, R.; Gish, T. Effects of corn on C-and L-band radar backscatter: A correction method for soil moisture retrieval. Remote Sens. Environ. 2010, 114, 2417-2430. [CrossRef]

45. Bindlish, R.; Barros, A.P. Parameterization of vegetation backscatter in radar-based, soil moisture estimation. Remote Sens. Environ. 2001, 76, 130-137. [CrossRef]

46. McNairn, H.; Duguay, C.; Brisco, B.; Pultz, T.J. The effect of soil and crop residue characteristics on polarimetric radar response. Remote Sens. Environ. 2002, 80, 308-320. [CrossRef] 
47. Baghdadi, N.; Cerdan, O.; Zribi, M.; Auzet, V.; Darboux, F.; El Hajj, M.; Kheir, R.B. Operational performance of current synthetic aperture radar sensors in mapping soil surface characteristics in agricultural environments: Application to hydrological and erosion modelling. Hydrol. Process. 2008, 22, 9-20. [CrossRef]

48. Marzahn, P.; Ludwig, R. On the derivation of soil surface roughness from multi parametric PolSAR data and its potential for hydrological modelling. Hydrol. Earth Syst. Sci. 2009, 13, 381-394. [CrossRef]

49. Durand, J.M.; Gimonet, B.J.; Perbos, J.R. SAR Data Filtering for Classification. IEEE Trans. Geosci. Remote Sens. 1987, 25, 629-637. [CrossRef]

50. Shi, Z.; Fung, K. A comparison of Digital Speckle filters. Int. Geosci. Remote Sens. Symp. 1994, $2129-2133$. [CrossRef]

51. Sheng, Y.; Xia, Z.G. A comprehensive Evaluation of Filters for Radar Speckle Suppression. Int. Geosci. Remote Sens. Symp. 1996, 1559-1561. [CrossRef]

52. Hagg, W.; Sties, M. The EPOS speckle filter: A comparison with some well-Known speckle reduction techniques. In International Archives of Photogrammetry and Remote Sensing, XXXI (Part B2); ISPRS: Vienna, Austria, 1996.

53. Lee, J.S. Refined filtering of image noise using local statistics. Comput. Graph. Image Process. 1981, 15, 380-389. [CrossRef]

54. Moran, P.A.P. Notes on continuous stochastic phenomena. Biometrika 1950, 37, 17-23. [CrossRef] [PubMed]

55. Huang, Y.; van Genderen, J.L. Evaluation of Several Speckle Filtering Techniques for ESR-1\&2 Imagery. In International Archives of Photogrammetry and Remote Sensing, XXXI (Part B2); ISPRS: Vienna, Austria, 1996.

56. Capodici, F.; D'Urso, G.; Maltese, A. Investigating the Relationship between X-Band SAR Data from COSMO-SkyMed Satellite and NDVI for LAI Detection. Remote Sens. 2013, 5, 1389-1404. [CrossRef]

57. Evans, J.D. Straightforward Statistics for the Behavioral Sciences; Brooks/Cole Publishing: Pacific Grove, CA, USA, 1996.

58. Naidoo, L.; Mathieu, R.; Main, R.; Kleynhans, W.; Wessels, K.; Asner, G.; Leblon, B. Savannah woody structure modelling and mapping using multi-frequency (X-, C- and L-band) Synthetic Aperture Radar data. ISPRS J. Photogramm. Remote Sens. 2015, 105, 234-250. [CrossRef]

59. Yueh, S.H.; Nghiem, S.V.; Kwok, R. Symmetrization of cross-polarized responses in polarimetric radar images using reciprocity. IEEE Trans. Geosci. Remote Sens. 1993, 31, 1180-1185. [CrossRef]

(C) 2017 by the authors. Licensee MDPI, Basel, Switzerland. This article is an open access article distributed under the terms and conditions of the Creative Commons Attribution (CC BY) license (http:/ / creativecommons.org/licenses/by/4.0/). 